\title{
Mass Appraisal, Hedonic Price Modelling and Urban Externalities: Understanding Property Value Shaping Processes
}

\author{
By \\ François Des Rosiers and Marius Thériault \\ Laval University, Canada \\ Discussion Paper presented at the \\ Advances in Mass Appraisal Methods Seminar, \\ Delft University of Technology, \\ October 30-31, 2006
}

\section{INTRODUCTION}

Since it was first applied on the automotive industry (Court 1939), more than six decades ago, the hedonic approach has rapidly developed as one of the most widely used analytical framework for estimating the implicit prices of attributes pertaining to heterogeneous goods. Considering the highly complex nature of real estate which consists of building, land and neighbourhood characteristics, it soon became a prime target for hedonic price modelling where it was applied for various purposes, among which the estimation of the marginal contribution of urban externalities - namely environmental ones - to market values. The introduction and the generalization of the personal computer in the late 1970s - early 1980s then allowed hedonics to spread and eventually dominate the development of computer assisted mass appraisal (CAMA) systems, first in the United-States and later on in the rest of the world, particularly where property values form the basis of the local tax system.

The popularity of hedonic price modelling for mass appraisal purposes stems from several factors. Firstly, it rests on multiple regression analysis (MRA), a conceptually sound and most powerful analytical device that combines probability theory with calculus, thereby allowing sorting out crossed influences that affect property values. Secondly, it perfectly fits the very definition of market value, expressed as "the most probable price" that should be paid for in a competitive and transparent market setting. A market value being a probability distribution, it calls for a statistical treatment which conveys objectivity through direct market reading, is easily reproducible and offers adequate testing of result reliability; MRA does provide for such qualities. Thirdly, the hedonic approach is not confined to producing value estimates as it adds most useful insights into the causal dimensions of property value determination. Thus, it is viewed as a decision making tool that brings about market intelligence, even more so when used 
in combination with geographic information systems (GIS), a "natural", and increasingly imperative, complement for adequately handling spatial issues.

In order to apply though, all these advantages require that somewhat restrictive assumptions be met. In short, variables as well as model residuals should be normally distributed, the relationship between the dependent variable and the descriptors should be linear, exogenous variables should be independent from one another while the error terms should be both independent and homoskedastic. The model's failure to comply with such restrictions due to the presence of excessive multicollinearity, heteroskedasticity and spatial autocorrelation may result in parameter estimates - that is, implicit prices of property attributes - not being reliable anymore. As shall be discussed later on, most problems encountered with MRA can be dealt with successfully through data transformation, appropriate market segmentation and adequate model specification as well as through resorting to suitable spatial modelling procedures.

Yet, the hedonic approach remains structurally bound to assuming a priori some functional relationship between sale prices and property attributes, based on either deductive or inductive grounds, or both. Whether this should be considered as a strength or a drawback of the method depends on the research "ideology" of the modeller; which is why hedonic price modelling, considered as the orthodox way in mass appraisal practice, is being challenged by other noneconometric, more flexible, approaches such as artificial neural networks (ANN) (Worzala et al., 1995), pattern recognition, fuzzy logic and rough set theory, all of which are data driven techniques, hence freed from the need to provide a theoretical explanation to value. Ultimately, this raises the following question: is understanding the dynamics of real estate markets prerequisite to reliably predicting property values?

In this paper, several methodological issues pertaining to hedonic price modelling are discussed in the light of past empirical research performed since 1995 in Quebec, Canada, and mainly in Quebec City. Section 1 looks at the rationale and conceptual framework underlying the hedonic approach. In Section 2, the functional form issue is addressed with particular reference to the measurement of proximity effects on house values. Section 3 looks at ways to account for a major determinant of property prices, namely accessibility to urban services. In Section 4, the spatial dependence issue is investigated and alternate modelling procedures designed at handling spatial autocorrelation are discussed. Finally, the paper concludes on the relevance of the hedonic approach for appraisal purposes. 


\section{Hedonic Price modelling - The Conceptual Framework}

While the formulation of the hedonic theory is associated with Rosen's (1974) seminal paper, the use of MRA for hedonic pricing can be traced back to Court (1939) who applied the concept to the automotive industry and, later on, to Stone (1956), Griliches (1961) and Lancaster (1966). Since then, Rosen's approach has been applied to a wide range disciplines, among which housing (Bajari and Kahn, 2005), public economics, environmental economics, labour markets and, to a lesser extent, marketing and industrial organization (Berry et al., 1995; Goettler and Shachar, 2001; Benkard and Bajari, 2005). Similarly, topics dealt with through hedonic price modelling prove to be most diverse, from estimating the value of urban air quality (Graves et al., 1988) to building price indexes (Griliches, 1971; Hoesli et al., 1997a) to analyzing market power and quality differentials in the food industry (Gorman, 1980; Nevo, 2001), to name just a few. Being, by and large, highly competitive with characteristics that are openly known to both buyers and sellers, the housing market turned out to be an ideal ground for applying hedonics. While singlefamily houses clearly dominate the hedonic literature, rental housing (Sirmans and Benjamin, 1989 \& 1991; Jud and Winkler, 1991; Des Rosiers and Thériault, 1996; Hoesli et al., 1997b) as well as commercial properties (Benjamin et al., 1990; Sirmans and Guidry, 1993; Mejia and Benjamin, 2002; Des Rosiers et al., 2005) have also been analyzed using the hedonic framework.

From a conceptual point of view, the hedonic theory applies to heterogeneous goods and rests upon the assumption that the market price of a complex good $(Z)$ is a direct function of the utility, or profit, derived from the quantity of the $n$ attributes it is composed of. The market price for $Z$ results from equilibrium between supply and demand, based on known characteristics. Each consumer, or buyer, is assigned a bid function $(\theta)$ reflecting his willingness-to-pay for the good with $\theta$ being expressed as a function of both the quantity of the $n$ attributes composing $Z$ and the level of utility $(\boldsymbol{v})$ derived for a given level of income $(y)$ and a given structure of preferences $(\alpha)$. The bid function may be written as follows:

$$
\theta=\theta\left(z_{1}, \ldots, z_{n}, v \cdot y, \alpha\right)
$$

Similarly, the individual supply function $(\phi)$ defines the minimal price a producer (seller) is willing to accept for $Z$ considering its attributes and the expected profit $(\pi)$, for a given production level ( $M)$ and cost function $(\beta) ; \phi$ may be written as follows:

$$
\phi=\phi\left(z_{1}, \ldots, z_{n}, \pi \cdot M, \beta\right)
$$


Market equilibrium is reached for each attribute at the tangency point of bid and supply functions.

In Exhibit 1, all dimensions other than the $Z_{l}$ attribute are held constant, with the dotted, envelope curve representing the hedonic, or implicit, price function for $Z_{l}$. Generalizing this scheme leads to a family of envelope curves (hedonic prices) whereby market equilibrium is reached for all $n$ attributes.

\section{Exhibit 1 : Determining Implicit Price for Attribute $z_{1}$}

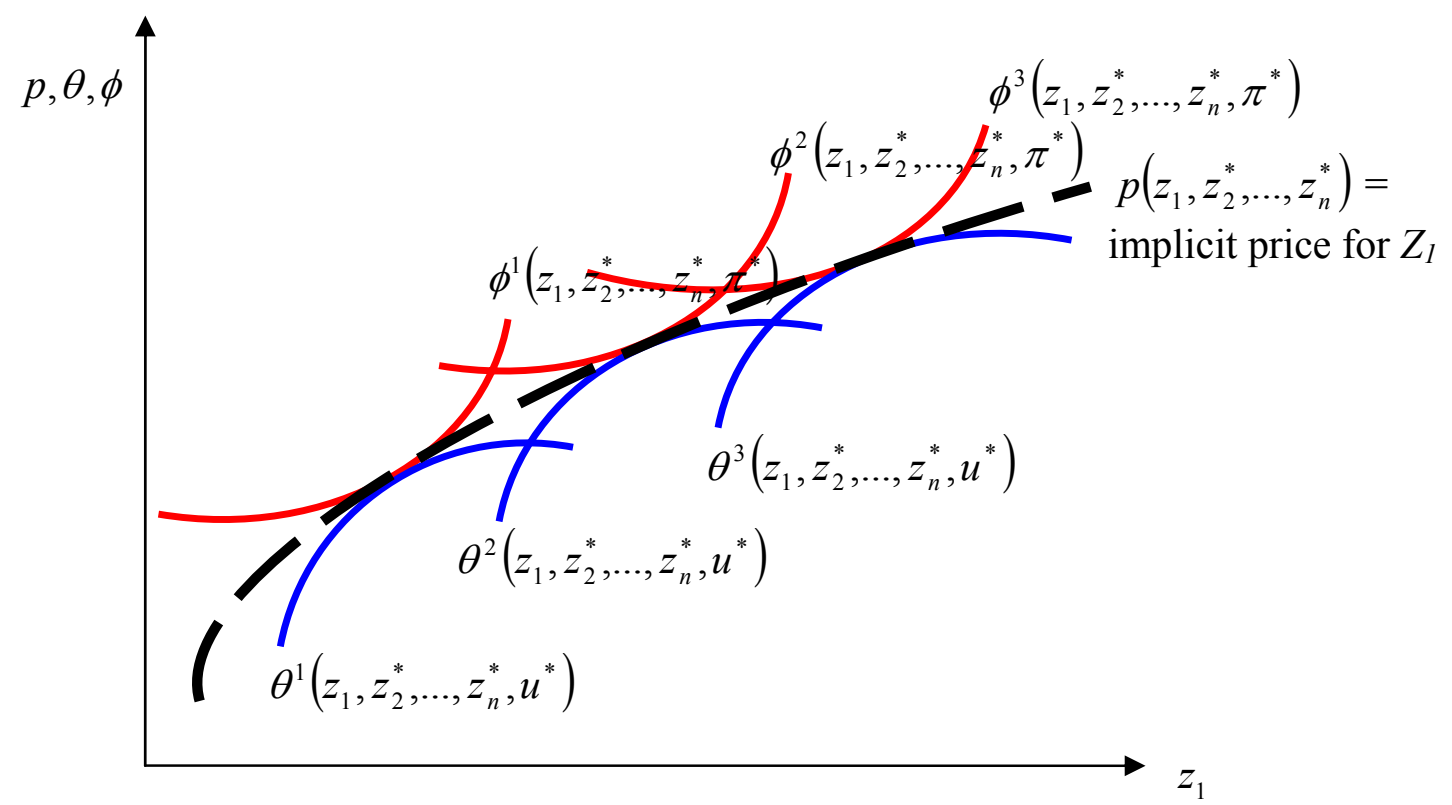

Rosen's (1974) contribution brought out two major limitations of the hedonic framework. Firstly, as displayed in Exhibit 1, the hedonic function amalgamates supply and demand factors, thereby inducing an identification problem. Secondly, the linearity of the hedonic function may be seriously questioned in light of empirical evidence pointing toward the non-linear behaviour of several phenomena, in particular with respect to the shaping of real estate values. For instance, the marginal contribution of either liveable area or lot size to house value is known to be decreasing. Finally, a third issue raised by Tyrvainen (1997) refers to the need for homogeneous household preferences to apply throughout the specific market under analysis for implicit prices to be derived. This is of paramount importance in an appraisal context since, as put by Epple and Platt (1998), households in any jurisdiction tend to differ in both preferences and income; not accounting for the heterogeneity dimension could then lead to severe fiscal inequities where appraised values are used for tax purposes. 
With respect to the first point, Straszheim (1987) argues that hedonic modelling practice has led to clearly distinguishing demand from supply determinants and that, anyway, implicit prices are actually estimated from the relationship for each housing attribute. As for the non-linearity and spatial heterogeneity issues, they are the focus of the following sections. 


\section{Urban EXTERnALITIES AND ThE FunCtionAL Form ISSUE - Measuring Proximity EfFects}

Richardson (1977), Berry and Bednarz (1979) as well as Hoch and Waddell (1993) all pointed out that rents and property values ultimately result, at any point in space, from the overlapping effect of access and neighbourhood attributes. Hence the particular emphasis laid upon neighbourhood, environmental and access variables in the hedonic literature. Indeed, measuring the extent to which urban externalities deriving from either residential or non-residential uses are capitalized into surrounding property values emerges as a dominant field of application for hedonics (Grether and Mieszkowski, 1980; Guntermann and Colwell, 1983; Colwell, Gujral and Coley, 1985; Colwell, 1990; Des Rosiers et al., 1996, 1999, 2000 \& 2001; Kestens et al., 2004); environmentoriented analyses, in particular, prove quite abundant (Des Rosiers, 2002; Simons and Saginor, 2006). In spite of the limitations of the method, it remains the most widely accepted tool for untangling the complex cross-influences between the numerous dimensions affecting property values and rents.

Investigating the effect of externalities on house values raises the fundamental issue of the functional form of the hedonic function (Linemann, 1980). While non-linearity in the parameters of the function will lead to using non-linear estimation procedures instead of the standard Ordinary Least Squares (OLS) method, non-linearity in the data may usually be handled successfully through some appropriate mathematical transformation on the variables. Indirectly though, coping with non-linearity calls for the market segmentation issue to be likewise addressed since the choice of a functional form may be sample-dependent. For that reason, market segmentation has also been well researched in the hedonic literature (Bajic, 1985; Adair, Berry and McGreal, 1996; Goodman and Thibodeau, 2003).

In this section, two cases will be considered based on previous research. In the first case study, the impact of a high voltage transmission line (HVTL) on house values is measured using dummy variables while the second case study involves a more sophisticated transformation meant at capturing the joint, non-monotonic influence of distance to, and size of, nearest primary school on values. 


\subsection{Measuring the Impact of a HVTL on House Prices}

\subsubsection{Context of study and database:}

Since 1990, there have been numerous hedonic analyses on estimating the impact of HVTLs on house values, among which those by Colwell (1990), Delaney and Timmons (1992), Hamilton and Schwann (1995), Kinnard and Dickey (1995) and Des Rosiers (2002). Most studies concentrate on estimating the lessening influence of a HVTL with increasing distance from the line or easement, using either discontinuous, dummy variables or some transformed continuous descriptor. While also dealing with that issue, Des Rosiers's (2002) study adopts a micro-spatial approach to impact measurement and focuses on what goes on along the line, using a series of dummy variables that describes in detail the position and orientation of the line and pylons relative to adjacent and nearby houses as well as the level of visual encumbrance to households.

The study is based on a sample of 507 single-family houses sold over the 1991-96 period in the City of Brossard (pop.: 69,000 by 1996), located in the Greater Montreal area, Canada, on the south shore of Saint-Lawrence River. The study area, which is between 250 and 500 metres wide, is bounded by three major highways, with a $315 \mathrm{Kv}$. transmission line running through its centre. Overall mean house price for the global sample stands at 169600 Can\$. The HVTL corridor itself is about three kilometres long and 60 metres wide, with IVA (Improved Visual Appearance) conical steel pylons reaching, in most cases, between 48 and 55 metres in height; within the study area, 26 such pylons are numbered. The span between pylons varies from 200 to 350 metres, minimal clearance between conductors and ground level standing from a low of 11 metres to a high of 20 metres. While the neighbourhood topography is flat with little tree planting around the HVTL structure, a cycling path is designed along its east side.

A major feature of this case study is the asymmetrical location of the line, which is within 50 metres of the eastern boundary of the easement, as opposed to 15 metres on the west side. Overall, 383 houses have a limited, moderate or pronounced - rear, side or front - view on the line, with 34 being directly adjacent to it. The average distance to the external boundary of the HVTL easement stands at 248 metres. The analysis includes some 25 property descriptors pertaining to physical, neighbourhood, environmental, access, fiscal and sales time attributes as well as a series of HVTL-related descriptors: linear distance to the line and easement as well as dummy distance variables (50 and $100 \mathrm{~m}$. increments) ; dummy variables to control for pylons' position relative to houses that are adjacent to the easement (house facing pylon, located one, two 
or three lots away from pylon, or mid-span located); and a series of interactive dummy descriptors to account for the combined extent of the view on the HVTL structures and the orientation of the property with respect to the easement. While both linear and log-linear functional forms were used, HVTL distance variables were also applied several transformations including logarithmic, square root, inverse, quadratic and gamma. The analysis was first performed on the global sample, and then on a series of submarkets, among which the east and west areas.

\subsection{2: Major findings:}

Some fifty models were calibrated, whose results are not shown here. Both explanatory and predictive performances prove excellent, with adjusted R-Squares being, by and large, well in excess of 0.90 while prediction error (SEE) usually stands well below 10 percent. All parameter estimates display signs and magnitudes that are in line with theoretical expectations. In particular, findings corroborate previous research in that they suggest that negative visual impacts on values - as measured with both dummy and continuous variables - tend to decrease rapidly with distance, and are no more significant beyond 150 metres. Findings also suggest that «net visual encumbrance» reaches a maximum for houses located between 50 and 100 metres from the easement boundary - with values dropping by some $5 \%$ to $12 \%$ of mean price - and tends to disappear beyond 150 metres.

Since our purpose here is to illustrate how location dummies allow for capturing discontinuous effects along the HVTL structure, we shall now focus on findings obtained for the global sample as well as for the east and west areas and pertaining to adjacent properties. By and large, the residential property which is both adjacent to a HVTL easement and facing a pylon (FACNGPYL) experiences a significant drop in value due to resulting visual encumbrance. This drop, which averages $9.6 \%$ of mean house price in the global sample, reaches $14 \%$ in the west area where a 15 metres setback with respect to the HVTL easement is found. In the east area however, characterized by a 50 metres setback, a direct view on a pylon has no significant impact on prices.

In contrast, a property located one or two lots away from a pylon (12LOTPYL) usually benefits from a market premium which mirrors the improved visual clearance and increased intimacy thus generated. Results obtained with the global sample show price increases averaging $11.6 \%$ (1LOTPYL) and 8.7\% (2LOTPYL) of mean house value, respectively. For adjacent properties belonging to the east area, being one lot distant from a pylon translates into a premium of $15.7 \%$ 
whereas no significant price impact is detected in the west area: due to a reduced setback, the pronounced visual encumbrance tends to cancel out proximity advantages. In turn, the premium is significant at a two-lot distance $(10.3 \%)$.

Finally, a property located three lots away from a pylon or at mid-span (3LOTMID) will, by and large, experience a significant price drop as a consequence of the visual encumbrance caused by conductors in the HVTL corridor section with low minimal clearance relative to ground level. Results obtained with the global sample suggest a $4.7 \%$ depreciation, as opposed to $7.7 \%$ in the east area. In the west area, a mid-span location (MIDSPAN) results in a 7.4\% price drop.

Exhibit 2 summarizes these findings, which, for the first time, tend to confirm on sound statistical grounds that being adjacent to a HVTL easement will not necessarily cause a house to depreciate and may even increase its value where proximity advantages (enlarged visual field, increased intimacy) exceed drawbacks. In this case, a micro-spatial approach resorting to location dummies proves an efficient way of capturing proximity effects.

\subsection{Coping With the Non-Monotonicity of the Hedonic Function - The Case of Primary Schools}

Our second example on the measurement of proximity effects investigates both school size and proximity to elementary schools as potential determinants of residential prices, with a focus on identifying the functional form that best accounts for the non-monotonicity of the hedonic function with respect to either parameters (Des Rosiers et al., 2001).

\subsubsection{Previous research and context of study:}

Relatively few authors have dealt with the impact that access to, and proximity of, primary schools exert on house values, and none has ever addressed the size issue, at least explicitly. Using 1,044 residential sales transacted between 1969 and 1977 in seven primary school neighbourhoods in western and south-western Lubbock, Texas, Guntermann and Colwell (1983) extensively investigate the impact primary schools have on house values. Their model includes an access variable - the inverse of the distance in miles to the nearest school - designed at capturing the fall in value beyond a critical distance $d^{*}$, as well as a variable which captures the negative externality effect within $d^{*}$. Thus, $d^{*}$ can be defined as that very distance where disadvantages due to school proximity are counterbalanced by the access factor. Findings indicate that both access and externality variables are statistically significant, giving a net accessibility effect over the entire area surrounding a primary school. This suggests that the access factor remains 


\section{Exhibit 2: Impact of HVTL Structures on the Market Value of Adjacent Properties}

- City of Brossard, Canada, 1991-1996

HVTL \% Impact

\section{Global Sample}

House facing pylon:

One lot away from pylon:

Two lots away from pylon:

Three lots away from pylon or mid-span location:
Attribute

FACNGPYL $\quad-9,6 \%$

1LOTPYL $\quad 11,6 \%$

2LOTPYL $\quad 8,7 \%$

3LOTMID $\quad-4,7 \%$

\section{East Area ( 150 ft. setback to HVTL)}

House facing pylon:

One lot away from pylon:

Two lots away from pylon:

Three lots away from pylon or mid-span location:
FACNGPYL

1LOTPYL

2LOTPYL

3LOTMID n.s.

$15,7 \%$

n.s.

$-7,7 \%$
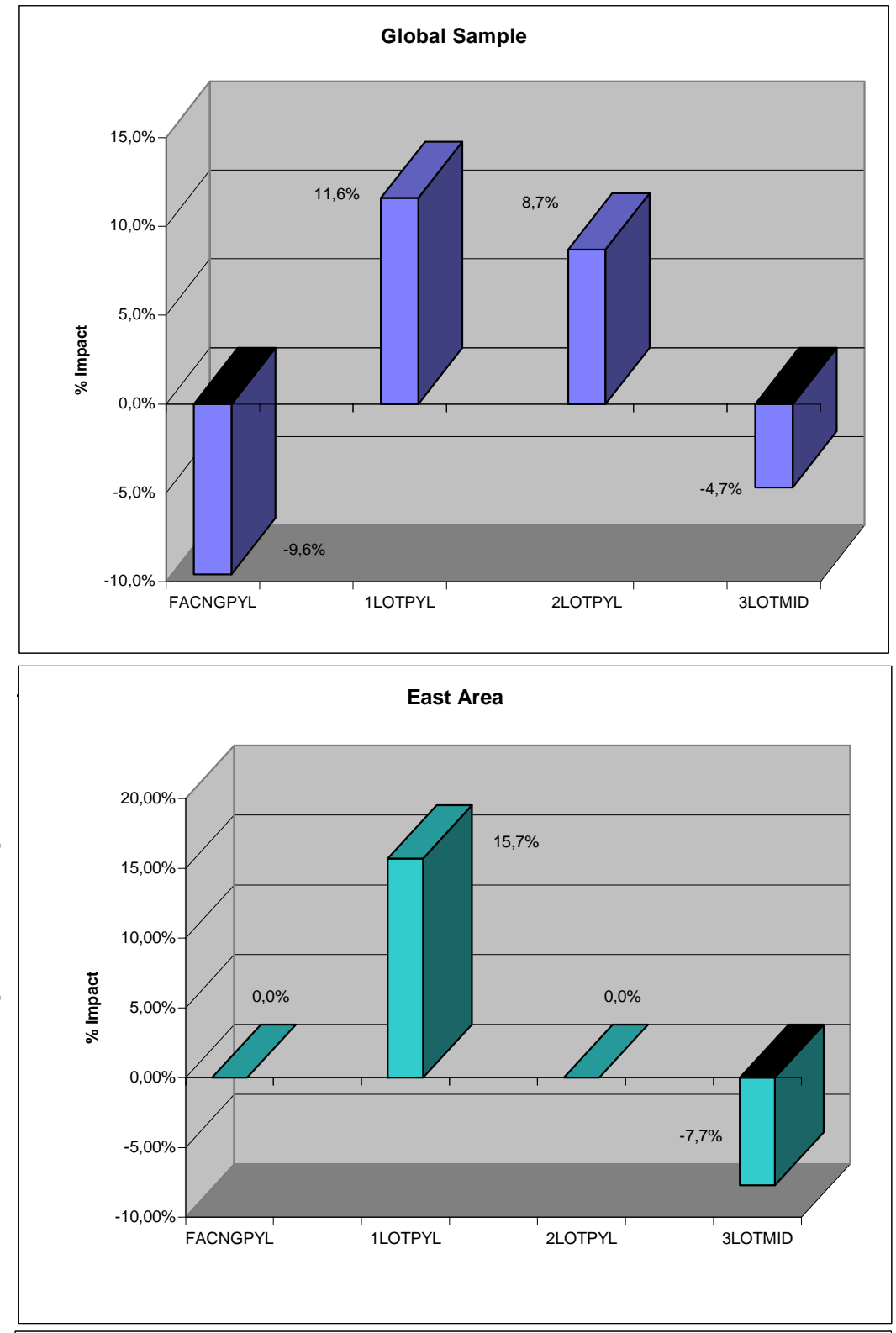

West Area

FACNGPYL $\quad-14,0 \%$

1LOTPYL n.s.

2LOTPYL $\quad 10,3 \%$

Two lots away from pylon:

MIDSPAN

(sig. 0.07)

Mid-span location:

$-7,4 \%$

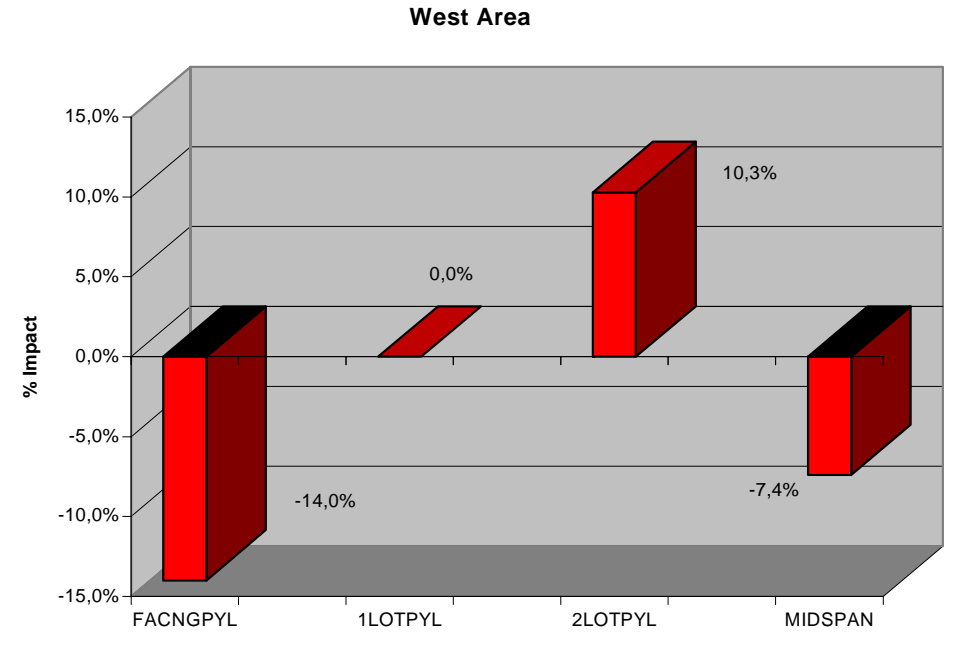

N.B.: 
overwhelming in guiding households' location choices. As for the value of $d^{*}$, it ranges from 165 to 1,320 feet from the school, with the maximum R-Squared being achieved at a $d^{*}$ of 742 feet.

The current study is based on a subset of some 4,300 bungalows (one-story, single-family detached houses) sold on the territory of the Quebec Urban Community (QUC, pop.: 675,000 by the time of study) between January 1990 and December 1991 and 116 elementary schools spread all over the territory. Sale price, used as the model dependent variable, ranges from a minimum of 35,000 to a maximum of 238,000 \$Can., with median price standing at 81,000\$Can. Up to 42 descriptors are used in the model, including detailed information on residential transactions, building and site characteristics, outbuildings, local tax rates, neighbourhood and access attributes as well as census (socio-economic) and environmental features. The spatial links between variables are processed via a regional GIS (Geographic Information System) equipped with spatial statistics capabilities (Des Rosiers and Thériault, 1995).

Primary schools are classified into three size categories: small (200 pupils and below), medium (201-500 pupils) and large ones (over 500 pupils). The vast majority of them (81) are mediumsize establishments, while small and large schools number 16 and 19 units, respectively. Euclidian distances to the nearest school, expressed in kilometres, are based on centroïd-tocentroïd calculations, not on distances to establishment outer peripheral boundaries. Although the measurement bias thus generated remains negligible in most cases, it should be borne in mind when interpreting distance coefficients - as well as optimal distances - pertaining to large schools.

\subsubsection{Handling non-monotonicity through a gamma transformation:}

While an easy access to a nearby school remains an overwhelming advantage for households with school-age children (Guntermann and Colwell, 1983), too great proximity to a school may be assumed to drive house prices down because of traffic, noise and, eventually, risk of damage to property. An optimal distance from school should then exist, whereby the net positive impact on house value is maximized. A similar rationale could be applied to school size, with both small and large school displaying advantages over middle-size institutions, which may be large enough to generate negative externalities without though providing adequate sporting amenities and after-school social interaction opportunities. If this is right, negative externalities ensuing from school size should reach a maximum for mid-size schools. 
Non-monotonicity is usually dealt with in the economic literature using a quadratic function. While relatively easy to handle within a linear analytical framework, such a function adequately captures nonlinear phenomena involving a minimum or a maximum, provided though these follow a symmetrical, regular pattern. Wherever it is not so, the quadratic form remains a quite rigid mathematical device which only imperfectly mirrors the reality. In the case of an elementary school, it is reasonable to assume that the negative externalities due to noise and traffic will affect house values downwards, but only within a relatively short radius from the establishment. In contrast, the drop in value beyond the optimal distance due to a reduced access is expected to be relatively smooth and to extend over a larger area. In other words, because location and amenity factors do not operate symmetrically in space, each portion of the pricedistance curve on either side of the function maximum should be expected to command substantially different slopes. A similar asymmetry may characterize the price-size relationship.

Modelling such a pattern requires a flexible tool, which can eventually adapt to various situations and research concerns. It will be shown here that the gamma transformation, which has been successfully applied in the case of shopping centres (Des Rosiers et al., 1996), meets these requirements.

\subsubsection{Solving for the price-distance relationship:}

The gamma distribution is a probability density function given by:

$$
\begin{aligned}
\mathbf{f}(\mathbf{x}) & =\mathbf{K} * \mathbf{x}(\alpha-1) \mathrm{e}^{(-\mathbf{x} / \beta)} & & \text { for } \mathbf{x}>0 \\
& =\mathbf{0} & & \text { for } \mathrm{x}=0,
\end{aligned}
$$

where $\alpha$ and $\beta$ are positive parameters and $K$ is a constant. It can be demonstrated that, for specific values of the parameters $\alpha$ and $\beta$, the gamma distribution turns into an exponential distribution, a chi-square distribution or even approaches a normal distribution. Moreover, the lower the value of $\beta$ the steeper the slope beyond the maximum. This is precisely the flexibility needed to deal with our research concern. In the following mathematical development, distance to the nearest primary school is used as the critical dimension to isolate, while all other descriptors are control variables. Integrating the gamma function into the hedonic equation results in a generalized gamma formulation which is given by:

$$
\text { SALEPRICE }=K_{1} * \operatorname{DSCHOOL}^{\left(\alpha_{1}-1\right)} \mathrm{e}^{\left(-\mathrm{DSCHOOL} / \beta_{1}\right)} * \Phi(\operatorname{SCHLSIZE}) \mathrm{e}^{\left(\Sigma \mathbf{B}_{\mathbf{i}} * \mathrm{Z}_{\mathbf{i}}+\mathrm{e}\right)}
$$


where $\Phi(S C H L S I Z E)$ is a function of school size - specified later on - while the $\Sigma B_{i} * Z_{i}$ term accounts for the control variables. Applying a logarithmic transformation then gives:

$$
\begin{aligned}
\text { LnSALEPRICE }= & \operatorname{Ln} K_{1}+\left(\alpha_{1}-1\right) \text { Ln DSCHOOL }- \text { DSCHOOL } / \beta_{1} \\
& +\operatorname{Ln} \Phi(\text { SCHLSIZE })+\sum B_{\mathrm{i}} Z_{\mathrm{i}}+\mathrm{e}
\end{aligned}
$$

The first derivative of the gamma function provides a measure of the "optimal" distance away from a nearby school in order for a property to have its value maximized. Optimal distance (DSCHOOL*) can be determined by solving for the first derivative set to zero. Thus, we can write:

$$
d \text { LnSALEPRICE } / d \text { DSCHOOL }=\left(\alpha_{1}-1\right) \text { 1/ DSCHOOL }-1 / \beta_{1}
$$

Hence: $\quad$ DSCHOOL $^{*}=\left(\alpha_{1}-1\right) \beta_{1}$

The mathematical requirement for a maximum to be reached though is that the second derivative of the function with respect to DSCHOOL be negative, which gives:

$$
d^{2} \text { LnSALEPRICE / } d \text { DSCHOOL } 2<0
$$

Hence: $\quad\left(\alpha_{1}-1\right) /$ DSCHOOL ${ }^{2}>0$

Because squared distance is always positive, this condition is met as long as the alpha parameter is greater than unity.

\subsubsection{Addressing the price-size relationship:}

Turning to the price-size issue, a similar gamma transformation is now performed on the size variable. In this case however, excessive collinearity between school size terms requires that it be adapted using the Box-Cox procedure (1964). The detailed procedure followed is reported in Des Rosiers et al. (2001).

The ensuing model thus provides for a double-gamma transformation expressed as:

$$
\begin{aligned}
\text { LnSALEPRICE } & =\operatorname{Ln~K} K_{1}+\left(\alpha_{1}-1\right) \text { Ln DSCHOOL }- \text { DSCHOOL } / \beta_{1} \\
& +\operatorname{Ln}\left(K_{2}-1 / 2 \beta_{2}\right)-\left(\alpha_{2}-1\right) \text { Ln SCHLSIZE } \\
& +\left(1 / 2 \beta_{2}\right) \text { SCHLSIZE } 2+\sum B_{i} Z_{i}+e
\end{aligned}
$$

where $\operatorname{Ln} K_{1}+\operatorname{Ln}\left(K_{2}-\mathbf{1} / \mathbf{2} \beta_{2}\right)=\delta$, 
which represents the constant term of the double-gamma transformation on both distance-toschool and school size. Solving for the first and second derivatives with respect to school size, we can write:

$$
d \text { LnSALEPRICE } / d \text { SCHLSIZE }=-\left(\alpha_{2}-1\right) / \text { SCHLSIZE }+ \text { SCHLSIZE } / \beta_{2}
$$

and:

$$
d^{2} \text { LnSALEPRICE } / d \text { SCHLSIZE } 2=\left(\alpha_{2}-1\right) / \text { SCHLSIZE } 2+1 / \beta_{2}>0
$$

Setting the first derivative to 0 , the value-minimizing school size can then be determined as follows:

$$
\text { SCHLSIZE }^{*}=\sqrt{ }\left(\alpha_{2}-1\right) \beta_{2}
$$

Overall model performances obtained with a semi-log functional form prove quite good (Adjusted R-Square: 0.832; SEE: 0.0985; F Ratio: 531.4), with 37 of the 40 independent variables emerging as statistically significant at the 0.001 level. As for collinearity, it is well under control; while VIFs are understandably higher for primary school variables, they remain within the critical threshold of 10 (Neter et al., 1985).

Substituting the double-gamma transformation for the initial distance-to-school and school size terms in the semi-log hedonic equation corroborates research assumptions, as shown in Exhibit 3. Findings provide strong empirical evidence that the gamma function efficiently captures households' residential preferences with respect to proximity of, and access to, primary schools. Most interestingly, house values are maximized at a 407 metres distance from the nearest school. Allowing for a walking pace of two kilometres an hour - a reasonable pace for a not-tooreluctant child -, this implies a twelve minutes walk from home. It is also consistent with the upper limit identified by the Guntermann and Colwell's (1983) study.

As for the modified gamma function applied to school size, findings suggest that negative proximity effects first increase with school size, reach a maximum at a critical size of 365 pupils and decrease thereafter. Again, they tend to corroborate Guntermann and Colwell's (1983) view that larger schools offer leisure services valued by households and which are therefore internalized into residential prices.

Exhibit 4 provides a useful illustration of both price-distance and price-size relationships. 
Exhibit 3: Main Regression Findings for Primary School Variables - Quebec Urban Community, Canada, 1990-1991

\begin{tabular}{|c|c|c|c|}
\hline Name of Variable & $\begin{array}{c}\text { Regression } \\
\text { Coefficient }\end{array}$ & T value & Probability $>|\mathbf{T}|$ \\
\hline LnDSCHOOL*** & 0.0275 & 5.62 & 0.000 \\
DSCHOOL*** & -0.0001 & -11.08 & 0.000 \\
LnSCHLSIZE** & -0.0207 & -2.17 & 0.030 \\
SCHLSIZE2** & 0.0000 & 2.09 & 0.036 \\
\hline Alpha & Beta & Optimal Distance (m.) \\
\hline Gamma parameters on & $\mathbf{1 . 0 3}$ & $\mathbf{1 4 7 8 2}$ & $\mathbf{4 0 7}$ \\
\hline Distance-to-school & $\mathbf{1 . 0 2}$ & $\mathbf{6 . 4 5 E}+\mathbf{0 6}$ & $\begin{array}{c}\text { Value Minimizing Size (\# pupils) } \\
\text { Gamma parameters on } \\
\text { School Size }\end{array}$ \\
\hline
\end{tabular}

Exhibit 4: House Values, Distance-to-School and School Size
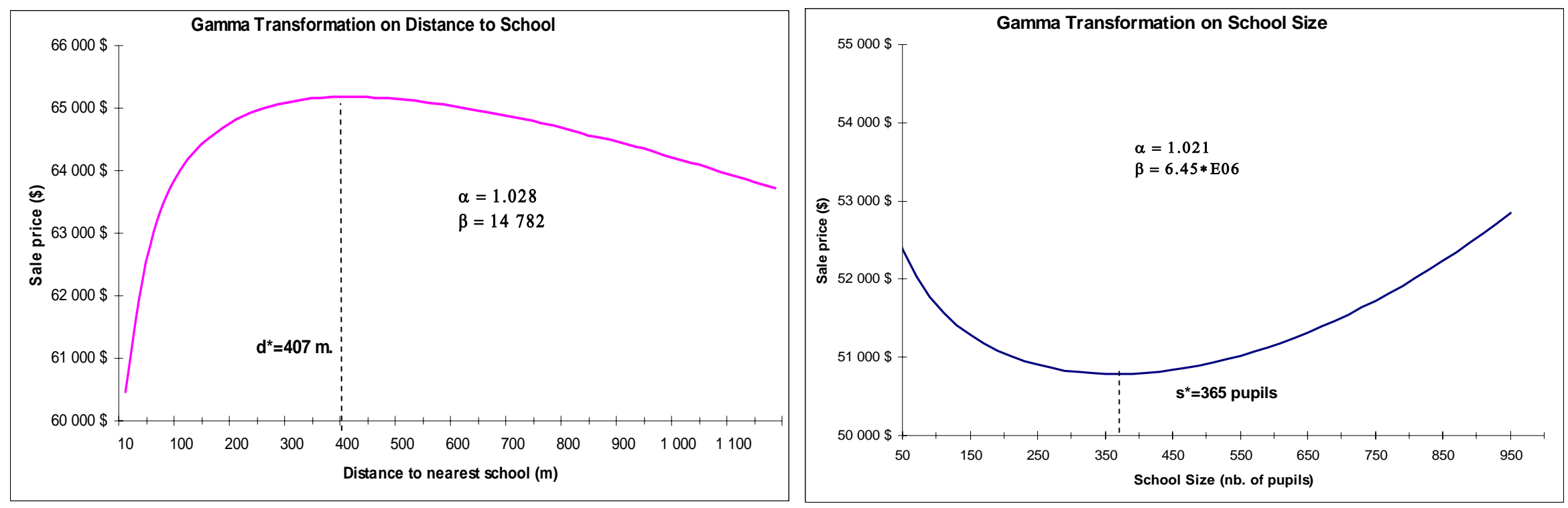


\section{Hedonic Modelling And ACCESSibility to Urban ServiceS}

\subsection{Defining Accessibility - Objective or Subjective Concept?}

Accessibility to goods and services is a complex notion which completely pervades territorial issues (Hansen, 1959); for that reason, it can be considered as one of the main determinants of property values (Des Rosiers et al., 2000), although its influence will differ depending on the configuration of the urban fabric (Kestens et al., 2004). Together, accessibility and mobility are central to understanding transportation and urban dynamics. Hanson (1995) points out that accessibility refers to the number of opportunities available within a certain distance or travel time while mobility refers to the ability to move between different activity sites. According to Levy and Lussault (2003) though, accessibility cannot be defined by itself since it depends on context-specific criteria: transportation networks and technology on the supply side; personal values, natural constrains (e.g. weather) and sociological acceptability on the demand side.

Previous research show that Euclidean distances to the CBD and various urban amenities, as well as travel times to schools and shopping centres, are useful, objective measures of the phenomenon which can be easily assessed using information from transportation networks. However, other perceptual, hence subjective dimensions are at stake, which are driven by households' preferences, family structure and life cycle as well as by income and motorization constraints. The resulting utility functions affect home location choices and, consequently, housing markets as a whole.

Accessibility is usually seen as an interaction potential mostly driven by socio-economic forces (Handy and Neimeier, 1997; Levinson, 1998). Thus, the accessibility potential of any location or attraction point - could be expressed as a direct function of the number of opportunities it offers as a destination for households while being inversely related to its distance (or travel time) to residential places. This forms the conceptual grounds for gravity models as applied in urban studies during the seventies (Curry, 1972; Cliff et al., 1974; Johnston, 1973). During the eighties, Fotheringham (1981 \& 1986) developed the behavioural theories needed to analyze competing destinations. For Boots and Kanaroglou (1988) as well as for Tiefelsdorf (2003) though, spatial structure effects explain much of the spatial heterogeneity in the distance decay patterns and should therefore be controlled for before accessibility measures are derived.

Research on accessibility leads to questioning the "objective", supply-driven definition which is traditionally attached to this concept. Rather than being viewed as homogeneous in space, it could 
be argued that accessibility to urban amenities is likely to vary according to the type of amenity considered (e.g. workplaces versus leisure places) as well as among social groups. If this is so, then how do both measures (i.e. supply-driven and demand-driven indices) compare as determinants of location rents and house prices? The following section investigates that issue. For that purpose, hedonic modelling is applied to some 952 single-family houses sold in Quebec City between 1993 and 1996. Firstly, a principal component analysis (PCA) is performed on a series of 15 travel time variables computed on the Quebec Metropolitan Area (QMA) road network, resulting in two supply-driven accessibility indices. Then, "subjective", demand-driven indices of accessibility based on actual purpose-specific trips made by individuals and households are built for Quebec City using fuzzy logic. A gravity-based centrality index is also designed as a control variable to be used jointly with the latter. House prices are finally regressed on a series of land, building and neighbourhood variables, with PCA-derived and demand-driven accessibility indices being used alternately in the equation.

\subsection{Using Factor Analysis to Derive Overall, Supply-Driven Accessibility Indices}

The regional GIS used for this study includes, among other things, detailed information on the QMA road and street network as of 1991. Using the TransCAD transportation-oriented software, it was possible to compute, for each property in our database, the best route (shortest distance and trip duration) to main employment centres, to schools, colleges and university as well as to neighbourhood, local and regional shopping centres. The computation algorithm developed for that purpose identifies 52,500 street segments (acting as directional links) and 19,250 nodes (acting as street intersections), of which 10,472 are within Quebec City's limits. Distances and travel times by car and on foot to the nearest amenity are computed for every street node in the network and then assigned to all related properties. Only travel times are considered in this paper.

As a result, 15 accessibility attributes are defined, as reported in Exhibit 5. Using these simultaneously in a single equation would of course induce severe collinearity in the model. To reduce its extent, one may limit the number of descriptors to a minimum, thereby causing a partial loss of information. Another option - developed here - is to resort to factor analysis (Thurstone, 1947; Rummel, 1970) in order to generate independent complex variables used as substitutes for initial attributes.

The principal components method (PCA), with a Varimax rotation, is thus applied to each initial travel time variable. Outlined by Hotelling (1933), this method essentially involves an orthogonal transformation of a set of variables $\left(\mathrm{x}_{1}, \mathrm{x}_{2}, \ldots, \mathrm{x}_{\mathrm{m}}\right)$ into a new set of mutually independent 
components, or factors $\left(\mathrm{y}_{1}, \mathrm{y}_{2}, \ldots, \mathrm{y}_{\mathrm{m}}\right)$ (King, 1969). Each component thus obtained consists of a linear combination of all initial variables (Tabachnick and Fidell, 1996) which are assigned a specific weight that vary among components. The first component is to have the highest variance among the " $\mathrm{m}$ " set of components, thereby accounting for a dominant portion of the variance observed in the data. The Varimax saturation obtained in the process for each variable and within each factor also indicates to what extent a given attribute contributes to the phenomenon captured by the factor. Only the most significant components will be retained by the analyst on the grounds of either their eigenvalue or percentage of variance explained.

The rotated factor analyses performed on access attributes result in two components being retained. As shown in Exhibit 5, they jointly explain more than 75 percent of the total variance, with Component (Factor) 1 accounting - after rotation - for 42 percent, as opposed to 33 percent for Component (Factor) 2. The information provided by the rotated component matrix points toward a quite straightforward interpretation: Factor 1 accounts for accessibility to regional services while Factor 2 refers to local accessibility.

\subsection{Resorting to Fuzzy Logic to Derive "Subjective” Accessibility Indices}

\subsubsection{The 2001 Origin-Destination survey:}

From mid September to mid December 2001, the Ministry of Transport of Quebec (MTQ) and the Quebec City Transit Authority (RTC) conducted a large Origin-Destination (O-D) survey involving 68,121 persons living in 27,839 households and describing 174,243 daily trips. Each household has its home located on a 1:20,000 map using street addresses. Each person belongs to a specific household and is characterized by his/her age, gender, occupation (worker, student, retired, unemployed, etc.) and ownership of a car driver licence. Households were ultimately classified as follows: lone person, childless couple, two-parent family (father and mother with children), lone-parent family (father or mother with children), and other households (either multi-generational or more than two adults, with and without children).

The origin and destination points of each trip reported by respondents are located in space using several geocoding methods yielding highly accurate spatial references (identifying either the building or the city block). Each trip is described by several attributes including its purpose (work, school, shopping, grocery, leisure, health care and restaurant), transportation mode (car driver, car passenger, walk, bus, bike, etc.) and departure time. Trip duration is estimated using a computational procedure (Thériault et al., 1999) linking origin and destination points of each trip 


\section{Exhibit 5: Using Factor analysis to Derive Overall Accessibility Indices}

Total Variance Explained

\begin{tabular}{rcccccc}
\hline \multirow{2}{*}{ Component } & \multicolumn{2}{c}{ Extraction Sums of Squared Loadings } & \multicolumn{3}{c}{ Rotation Sums of Squared Loadings } \\
\cline { 2 - 7 } & Total & \% of Variance & Cumulative \% & Total & \% of Variance & Cumulative \% \\
\hline 1 & 9.683 & 64.556 & 64.556 & 6.313 & 42.086 & 42.086 \\
2 & 1.668 & 11.122 & 75.678 & 5.039 & 33.592 & 75.678 \\
\hline
\end{tabular}

Extraction Method: Principal Component Analysis.

\section{Rotated Component Matrix a}

\begin{tabular}{lll}
\hline & \multicolumn{2}{c}{ Component } \\
\cline { 2 - 3 } & 1 & 2 \\
\hline Travel time to nearest highway entrance by car (minutes) & .6466 & .3518 \\
Travel time to nearest regional shopping center by car (minutes) & .7584 & .5554 \\
Travel time to nearest local shopping center by car (minutes) & .5572 & .7276 \\
Travel time to nearest neighbourhood shopping center by car (minutes) & .5455 & .6708 \\
Travel time to nearest highschool by car (minutes) & .3511 & .7967 \\
Travel time to nearest college or university by car (minutes) & .9107 & .2421 \\
Travel time to Laval University by car (minutes) & .9156 & .2737 \\
Travel time to Downtown Quebec by car (minutes) & .6101 & .5335 \\
Travel time to Downtown Ste-Foy by car (minutes) & .8933 & .1427 \\
Travel time to La Capitale shopping center by car (minutes) & .3198 & .7009 \\
Walking time to nearest neighbourhood shopping center (minutes) & .4070 & .7762 \\
Walking time to nearest primary school (minutes) & .0106 & .7237 \\
Walking time to nearest highschool (minutes) & .2733 & .8475 \\
Walking time to nearest college or university (minutes) & .8009 & .2968 \\
Walking time to Laval University (minutes) & .8753 & .3606 \\
\hline
\end{tabular}

Extraction Method: Principal Component Analysis.

Rotation Method: Varimax with Kaiser Normalization.

a. Rotation converged in 3 iterations. 
to the nearest street corner. The best route, expressed as the shortest distance $(\mathrm{km})$ and duration (minutes), is then computed on this basis and added to the GIS.

Previous research (Thériault et al., 2005) clearly suggests that trip durations significantly differ between purposes as well as among individual and household profiles, thereby reinforcing the idea that accessibility is not homogeneous and that "objective", supply-driven measures may not be sufficient to capture trip-specific behavioural patterns.

\subsubsection{Designing perceptual accessibility indices:}

In as much as perception of accessibility fluctuates with the valuation each individual or household puts on each activity (trip purpose) and destination suitability, then travel time is a derived demand (Axhausen and Gärling, 1992). As pointed out by Kim and Kwan (2003), accessibility measurements should incorporate travel time thresholds since people adjust their willingness to travel according to the duration of both activities and trips. Developing a flexible methodology which includes personal trip duration thresholds associated with physical simulation of best-suited routes can thus enhance our understanding of accessibility. That is the purpose of this sub-section. With this in mind, we operationally define accessibility as the ease with which persons, living at a given location, can move to reach activities and services which they consider as most important.

Such a definition makes accessibility, a mostly behavioural and subjective concept, quite distinct from centrality which mainly relies on structural features and relates to proximity to urban amenities. In order to measure demand-driven accessibility, a procedure is designed which uses median and $90^{\text {th }}$ percentile ranks to qualify travel distance satisfaction thresholds. At this point, the choice for specific thresholds remains arbitrary but it could be made more rigorous if empirical data on travel behaviour were available. For the purpose of this paper, it is assumed that [1] any travel time smaller than the observed median $\left(C_{50}\right)$ during the O-D survey leads to an acceptable destination; [2] a travel time larger than the $90^{\text {th }}$ percentile of actually reported trip $\left(C_{90}\right)$ is likely to be unsatisfactory; and [3] that intermediate cases yield satisfactory levels obtained through linear interpolation (fuzzy membership).

Suitability indices may thus be expressed as:

$$
S_{i j}=1 \quad \forall D_{i j} \leq C_{50}
$$




$$
\begin{aligned}
& S_{i j}=1-\left(\frac{D_{i j}-C_{50}}{C_{90}-C_{50}}\right) \quad \forall C_{50}<D_{i j}<C_{90} \\
& S_{i j}=0 \quad \forall D_{i j} \geq C_{90}
\end{aligned}
$$

where:

$S_{i j}$ : $\quad$ Suitability index of travelling from residential location $i$ to activity location $j$

$D_{i j}$ : Travel time by car from residential location $i$ to activity location $j$ (minutes)

$C_{50}: 50^{\text {th }}$ percentile of the observed car travel durations (minutes)

$C_{90}: 90^{\text {th }}$ percentile of the observed car travel durations (minutes)

Computing the sum of suitability indices over every service locations assesses the raw suitability of each residential location (Equation 16). Equation 17 is used to rescale values between 0 and 100, using the city-wide maximum local raw suitability value as the denominator. This procedure is applied to every set of trip purpose and type of individual or household reported in the O-D survey. Maps were built for each accessibility index. Provided examples are Exhibits 5a (to restaurants) and $5 b$ (to the labour market of women and men).

$$
A_{i}=\sum_{j=1}^{m} S_{i j} P_{j} \quad, \quad i \in 1, \ldots, n \quad j \in 1, \ldots, m \text {, where: }
$$

$\boldsymbol{A}_{\boldsymbol{i}}: \quad$ Raw suitability of residential location $i$ (sum of suitable weighted opportunities)

and :

$$
A_{i}^{*}=100\left(A_{i} / \max \left(A_{1}, A_{2}, \ldots, A_{n}\right)\right) \quad, \quad i \in 1, \ldots, n, \text { where: }
$$

$\boldsymbol{A}_{i}{ }^{*}:$ Accessibility index of residential location $i$ relative to the most suitable place.

\subsubsection{Controlling for urban centrality :}

While accessibility and urban centrality are two distinct concepts, purpose-specific accessibility indices (e.g. accessibility to jobs) may to some extent capture part of urban centrality features; hence the need to control for the latter. In this study, a gravity-based model of interaction flows proposed by Tiefelsdorf (2003) is developed in order to account for interactions between any pair of residential and activity places. The following formulation assumes that [1] individual flows are independent from one another and that [2] interaction flows between any pairs of places are mutually independent (Thériault et al., 2005; Tiefelsdorf, 2003). Considering the actual features 
of Quebec City's road and highway networks, such assumptions are viewed as realistic. Thus, we can put:

$$
\mu_{i j}=\frac{e^{\lambda} P_{i}^{\lambda_{o}^{p}} P_{j}^{\lambda_{d}^{p}}}{D_{i j}^{\lambda^{d}}}, \text { where: }
$$

$\mu_{i j}: \quad$ Expected number of car trips between locations $i$ and $j$

$P_{i}$ : Total population at residential location $i$

$P_{j}: \quad$ Total number of potential activities at location $j$

$D_{i j}$ : Travel time by car from residential location $i$ to activity location $j$ (minutes)

Estimation of parameters was done using actual car-based trips reported by inhabitants of Quebec City during the O-D survey. In order to reduce the heaviness of the mathematical treatment involved by this operation, a 500 metres-radius hexagonal grid covering the entire QMA was created, resulting in 563 residential grid cells within Quebec City and 533 activity cells (work places and other amenities) within the QMA being defined. Each O-D location was then assigned to one cell and cell-to-cell travel times between home and activity centres were modelled using local street corners. Finally, O-D survey data were expanded (Thériault and Des Rosiers, 2004) in order to provide a reliable estimate of residential and activity potentials of each grid cell.

For each residential location, summing potential flows over all activity places provides an estimate of interaction with the overall urban amenities from that place (Equation 19). Equation 20 rescales values between 0 and 100, using the city-wide local maximum estimated flow as the denominator.

$$
M_{i}=\sum_{j=1}^{m} \mu_{i j} \quad, \quad i \in 1, \ldots, n \quad j \in 1, \ldots, m \text {, where: }
$$

$M_{i}: \quad$ Estimated total flow for residential location $i$

$n: \quad$ Number of residential locations

$m: \quad$ Number of activity locations

$$
M_{i}^{*}=100\left(M_{i} / \max \left(M_{1}, M_{2}, \ldots, M_{n}\right)\right) \quad, \quad i \in 1, \ldots, n, \text { where: }
$$

$\boldsymbol{M}_{i}{ }^{*}$ : $\quad$ Centrality index of residential location $i$ relative to the maximum potential. 


\subsection{Hedonic Price Modelling and Accessibility - Comparing the Two Approaches}

In this section, a series of twelve hedonic price models are built in order to test the appropriateness of accessibility and centrality indices. The database consists of a randomly selected sample of 952 single-family houses sold within the Quebec City limits between 1993 and 1996. Typical physical attributes are used as property descriptors (lot size, architectural type, living area, apparent age, number of washrooms, presence of a fireplace, excavated pool, attached or detached, single or double garage, etc.). A time variable (Month93Jan) is also included in order to assess the temporal drift on sale prices which, over that period, experienced a sustained drop. Finally, the overall, unstandardized local tax rate (OvllTaxRate) accounts for differentials in the local tax burden among the 13 municipalities forming the then QUC and which have since then been amalgamated in 2002 . Considering that sale prices range from $\$ 50,000$ to $\$ 460,000$, a semi$\log$ functional form is used with the natural logarithm of sale price as the dependent variable.

Model 1 includes only building, time and fiscal attributes. In Model 2, CPA-derived accessibility indices are added on. Finally, Models 3 to 12 combine specific, demand-driven accessibility indices - expressed as interactions between trip purpose and household profile-with the centrality index. Due to excessive collinearity, the latter could not enter Model 2. Overall model performances and full regression results for Models 1 to 3 are reported in Exhibit 6 while Exhibit 7 only reports regression results pertaining to accessibility and centrality indices obtained with Models 4 to 12 .

As can be seen from Model 1, all property-specific coefficients as well as time and taxation variables emerge as highly significant, with signs and magnitudes being in line with theoretical expectations. As expected, living area, apparent age and overall tax rate explain a large proportion of price variations. When added on, Access Factors 1 and 2 (Model 2), reflecting physical accessibility to regional and local amenities, respectively, substantially improve model performances while leaving most coefficients unchanged. As for findings from Models 3 to 12 , they clearly suggest that, even when controlling for urban centrality, accessibility to work and to other amenities emerge as significant, positive determinants of house values, thereby corroborating the view that accessibility is heterogeneous by nature. Moreover, it is worth noting that perceptual indices of accessibility far outweigh the centrality index, as shown by the Beta coefficients in Exhibit 7. 
To summarize, while PCA-derived, objective measures of accessibility based on travel time to the nearest facility yield good results from a merely statistical point of view, perceptual accessibility indices obtained with fuzzy logic allow to investigate commuting patterns and travel behaviour with greater insight and to design indicators of accessibility that are trip-purpose and householdstatus specific. 
Exhibit 6: Modelling the Effect of Accessibility on House Prices

Model Summary and Regression Results (Dependent Variable: LnSalePrice \$)

\begin{tabular}{|c|c|c|c|c|c|c|c|}
\hline Model & R & R Square & Adjusted R Square & F Value & Prob. & SEE & Maximum VIF \\
\hline 1 & .858 & .736 & .731 & 144.49 & .002 & .17959 & 3.050 \\
2 & .884 & .782 & .777 & 166.95 & .008 & .16330 & 3.053 \\
3 & .874 & .763 & .758 & 142.63 & .003 & .17040 & 3.060 \\
\hline
\end{tabular}

\begin{tabular}{|c|c|c|c|c|c|c|c|c|c|c|c|c|}
\hline & \multicolumn{4}{|c|}{ Model 1} & \multicolumn{4}{|c|}{ Model 2} & \multicolumn{4}{|c|}{ Model 3} \\
\hline & $\begin{array}{l}\text { Unstdz. } \\
\text { B }\end{array}$ & $\begin{array}{l}\text { Std. } \\
\text { Error }\end{array}$ & $\begin{array}{l}\text { Standzd. } \\
\text { Beta }\end{array}$ & $\begin{array}{c}t \\
\text { Value }\end{array}$ & $\begin{array}{l}\text { Unstdz. } \\
\text { B }\end{array}$ & $\begin{array}{l}\text { Std. } \\
\text { Error }\end{array}$ & $\begin{array}{l}\text { Standzd. } \\
\text { Beta }\end{array}$ & $\begin{array}{c}t \\
\text { Value }\end{array}$ & $\begin{array}{l}\text { Unstdz. } \\
\text { B }\end{array}$ & $\begin{array}{l}\text { Std. } \\
\text { Error }\end{array}$ & $\begin{array}{l}\text { Standzd. } \\
\text { Beta }\end{array}$ & $\begin{array}{c}t \\
\text { Value }\end{array}$ \\
\hline (Constant) & 11.68731 & .04746 & & 246.3 & 11.55619 & .05250 & & 220.1 & 11.50028 & .05038 & & 228.3 \\
\hline LotSize $\left(m^{2}\right)$ & .00003 & .00002 & .031 & 1.6 & .00008 & .00002 & .078 & 4.3 & .00008 & .00002 & .080 & 4.2 \\
\hline Bungalow * Living Area & .00235 & .00018 & .357 & 13.3 & .00231 & .00016 & .351 & 14.4 & .00228 & .00017 & .346 & 13.6 \\
\hline Cottage * Living Area & .00249 & .00013 & .569 & 19.4 & .00250 & .00012 & .571 & 21.3 & .00247 & .00012 & .565 & 20.2 \\
\hline Attached * Living Area & .00149 & .00027 & .101 & 5.5 & .00098 & .00025 & .067 & 3.9 & .00112 & .00026 & .076 & 4.3 \\
\hline Apparent Age & -.00387 & .00057 & -.138 & -6.8 & -.00853 & .00062 & -.303 & -13.8 & -.00662 & .00060 & -.235 & -11.0 \\
\hline \# Washrooms & .09517 & .01252 & .144 & 7.6 & .07281 & .01151 & .110 & 6.3 & .08150 & .01197 & .124 & 6.8 \\
\hline \#Fireplace & .05082 & .01209 & .079 & 4.2 & .04970 & .01101 & .077 & 4.5 & .05106 & .01149 & .079 & 4.4 \\
\hline Hard Wood Stair & .07454 & .01623 & .096 & 4.6 & .05922 & .01489 & .076 & 4.0 & .06646 & .01544 & .085 & 4.3 \\
\hline High Quality Floor & .06689 & .01295 & .097 & 5.2 & .04912 & .01185 & .071 & 4.1 & .05814 & .01232 & .084 & 4.7 \\
\hline LargeTerrace & .12394 & .04813 & .045 & 2.6 & .10813 & .04382 & .039 & 2.5 & .10856 & .04577 & .039 & 2.4 \\
\hline Brick Ext. Walls ( $\geq 51 \%)$ & .04567 & .01420 & .064 & 3.2 & .03660 & .01294 & .051 & 2.8 & .04089 & .01349 & .057 & 3.0 \\
\hline Clapbord Ext. Walls ( $\geq 51 \%)$ & -.05414 & .01565 & -.069 & -3.5 & -.04675 & .01425 & -.060 & -3.3 & -.05210 & .01489 & -.067 & -3.5 \\
\hline Single Attached Garage & .13307 & .02731 & .085 & 4.9 & .11599 & .02488 & .074 & 4.7 & .12187 & .02598 & .078 & 4.7 \\
\hline Double Attached Garage & .16945 & .03793 & .080 & 4.5 & .13446 & .03459 & .063 & 3.9 & .15802 & .03626 & .074 & 4.4 \\
\hline Double Detached Garage & .10959 & .03132 & .062 & 3.5 & .12144 & .02857 & .069 & 4.3 & .11030 & .02974 & .062 & 3.7 \\
\hline Excavated Pool & .18383 & .02617 & .125 & 7.0 & .16487 & .02386 & .112 & 6.9 & .16491 & .02495 & .112 & 6.6 \\
\hline Month93Jan & -.00184 & .00045 & -.070 & -4.0 & -.00167 & .00041 & -.063 & -4.1 & -.00191 & .00043 & -.072 & -4.5 \\
\hline OvTaxRate & -.25656 & .01589 & -.292 & -16.1 & -.14557 & .02068 & -.166 & -7.0 & -.25032 & .01575 & -.285 & -15.9 \\
\hline $\begin{array}{l}\text { Acces_Factor1 (Reg. services) } \\
\text { Acces_Factor2 (Local services) }\end{array}$ & & & & & $\begin{array}{l}.12485 \\
.04177\end{array}$ & $\begin{array}{l}.00959 \\
.00871\end{array}$ & $\begin{array}{l}.322 \\
.090\end{array}$ & $\begin{array}{r}13.0 \\
4.8\end{array}$ & & & & \\
\hline AWork * NoWorkerHld & & & & & & & & & .00287 & .00042 & .181 & 6.8 \\
\hline AWork * WorkerHld & & & & & & & & & .00273 & .00035 & .216 & 7.7 \\
\hline Centrality Index & & & & & & & & & .00173 & .00051 & .068 & 3.4 \\
\hline
\end{tabular}




\section{Exhibit 7: Summary of Regression Results for Perceptual Accessibility and Centrality Indices}

\begin{tabular}{|c|c|c|c|c|c|c|c|}
\hline Model & $\begin{array}{c}\text { Accessibility / Centrality } \\
\text { Index }\end{array}$ & $\begin{array}{c}\text { R } \\
\text { Square }\end{array}$ & SEE & $\begin{array}{l}\text { Unstdz. } \\
\text { B }\end{array}$ & $\begin{array}{l}\text { Standzd. } \\
\text { Beta }\end{array}$ & $\begin{array}{c}t \\
\text { Value }\end{array}$ & VIF \\
\hline $\begin{array}{c}3 \\
\text { Workplaces * Hsld Profile }\end{array}$ & $\begin{array}{l}\text { AWork * NoWorkerHld } \\
\text { AWork * WorkerHld } \\
\text { Centrality Index }\end{array}$ & .758 & .1704 & $\begin{array}{l}.00287 \\
.00273 \\
.00173\end{array}$ & $\begin{array}{l}.181 \\
.216 \\
.068\end{array}$ & $\begin{array}{l}6.8 \\
7.7 \\
3.4\end{array}$ & $\begin{array}{l}2.752 \\
3.061 \\
1.575\end{array}$ \\
\hline $\begin{array}{c}4 \\
\text { Schools * Family Status }\end{array}$ & $\begin{array}{l}\text { ASchool } * \text { Family } \\
\text { ASchool } * \text { ChildlessHld } \\
\text { Centrality Index }\end{array}$ & .765 & .1678 & $\begin{array}{l}.00333 \\
.00255 \\
.00146\end{array}$ & $\begin{array}{l}.279 \\
.220 \\
.058\end{array}$ & $\begin{array}{l}9.6 \\
8.0 \\
2.9\end{array}$ & $\begin{array}{l}3.431 \\
3.068 \\
1.572\end{array}$ \\
\hline $\begin{array}{c}5 \\
\text { Large Shops * Family Status }\end{array}$ & $\begin{array}{l}\text { ALargeShop * Family } \\
\text { ALargeShop } * \text { ChildlessHld } \\
\text { Centrality Index }\end{array}$ & .758 & .1702 & $\begin{array}{l}.00230 \\
.00235 \\
.00172\end{array}$ & $\begin{array}{l}.186 \\
.138 \\
.068\end{array}$ & $\begin{array}{l}7.9 \\
6.0 \\
3.4\end{array}$ & $\begin{array}{l}2.200 \\
2.059 \\
1.581\end{array}$ \\
\hline $\begin{array}{c}6 \\
\text { Small Shops }\end{array}$ & $\begin{array}{l}\text { ASmallShop } \\
\text { Centrality Index }\end{array}$ & .759 & .1698 & $\begin{array}{l}.00276 \\
.00152\end{array}$ & $\begin{array}{l}.168 \\
.060\end{array}$ & $\begin{array}{l}8.2 \\
3.0\end{array}$ & $\begin{array}{l}1.655 \\
1.616\end{array}$ \\
\hline $\begin{array}{c}7 \\
\text { Groceries * Family Status }\end{array}$ & $\begin{array}{l}\text { AGrocery } * \text { Family } \\
\text { AGrocery } * \text { ChildlessHld } \\
\text { Centrality Index }\end{array}$ & .756 & .1710 & $\begin{array}{l}.00257 \\
.00222 \\
.00157\end{array}$ & $\begin{array}{l}.185 \\
.130 \\
.062\end{array}$ & $\begin{array}{l}7.3 \\
5.4 \\
3.0\end{array}$ & $\begin{array}{l}2.479 \\
2.281 \\
1.685\end{array}$ \\
\hline $\begin{array}{c}8 \\
\text { Leisure * Family Status }\end{array}$ & $\begin{array}{l}\text { ALeisure * Family } \\
\text { ALeisure } * \text { ChildlessHld } \\
\text { Centrality Index }\end{array}$ & .762 & .1689 & $\begin{array}{l}.00290 \\
.00272 \\
.00143\end{array}$ & $\begin{array}{l}.242 \\
.193 \\
.056\end{array}$ & $\begin{array}{l}8.8 \\
7.3 \\
2.8\end{array}$ & $\begin{array}{l}3.001 \\
2.804 \\
1.618\end{array}$ \\
\hline $\begin{array}{c}9 \\
\text { Health care * Family Status }\end{array}$ & $\begin{array}{l}\text { AHealthCare * Family } \\
\text { AHealthCare } * \text { ChildlessHld } \\
\text { Centrality Index }\end{array}$ & .766 & .1673 & $\begin{array}{l}.00342 \\
.00262 \\
.00124\end{array}$ & $\begin{array}{l}.265 \\
.199 \\
.049\end{array}$ & $\begin{array}{l}9.9 \\
7.9 \\
2.4\end{array}$ & $\begin{array}{l}2.947 \\
2.574 \\
1.618\end{array}$ \\
\hline $\begin{array}{c}10 \\
\text { Restaurants }\end{array}$ & $\begin{array}{l}\text { ARestaurant } \\
\text { Centrality Index }\end{array}$ & .768 & .1668 & $\begin{array}{l}.00323 \\
.00120\end{array}$ & $\begin{array}{l}.212 \\
.047\end{array}$ & $\begin{array}{r}10.1 \\
2.4\end{array}$ & $\begin{array}{l}1.801 \\
1.608\end{array}$ \\
\hline $\begin{array}{c}11 \\
\text { Workplaces * Age Groups }\end{array}$ & $\begin{array}{l}\text { AWork * Age34less } \\
\text { AWork* Age35-44 } \\
\text { AWork* Age } 45-54 \\
\text { AWork* Age55more }\end{array}$ & .757 & .1704 & $\begin{array}{l}.00220 \\
.00301 \\
.00324 \\
.00317\end{array}$ & $\begin{array}{l}.155 \\
.306 \\
.318 \\
.194\end{array}$ & $\begin{array}{l}5.9 \\
9.0 \\
9.7 \\
8.1\end{array}$ & $\begin{array}{l}2.698 \\
4.507 \\
4.236 \\
2.229\end{array}$ \\
\hline $\begin{array}{c}12 \\
\text { Workplaces * Hsld Income }\end{array}$ & $\begin{array}{l}\text { AWork } \\
\text { AWork } * \text { Income }<60 \mathrm{~K} \$ \\
\text { AWork } * \text { Income } 60-80 \mathrm{~K} \$ \\
\text { AWork } * \text { Income } 80-100 \mathrm{~K} \$ \\
\text { AWork * income }>100 \mathrm{~K} \$ \\
\text { Centrality Index }\end{array}$ & .771 & .1655 & $\begin{array}{r}.00311 \\
-.00111 \\
-.00060 \\
-.00029 \\
.00074 \\
.00192\end{array}$ & $\begin{array}{r}.179 \\
-.098 \\
-.050 \\
-.021 \\
.060 \\
.076\end{array}$ & $\begin{array}{r}8.3 \\
-4.7 \\
-2.5 \\
-1.1 \\
2.9 \\
3.9\end{array}$ & $\begin{array}{l}1.914 \\
1.811 \\
1.682 \\
1.544 \\
1.737 \\
1.582\end{array}$ \\
\hline
\end{tabular}




\section{Spatial Dependence - How to Deal With It}

\subsection{Market Heterogeneity and Spatial Dependence}

As emphasized in the introduction to this paper, applying the hedonic approach raises major methodological issues in relation to the presence of structural heteroskedasticity and spatial autocorrelation in the model residuals. Both are detrimental to the stability of regression coefficients, even more so to the accuracy of their standard errors (Dubin, 1988 \& 1992; Anselin and Rey, 1991; Goodman and Thibodeau, 1995 \& 1997; Can and Megbolugbe, 1997; Basu and Thibodeau, 1998; Pace et al., 1998; Des Rosiers and Thériault, 1999).

In traditional hedonic price modelling, the contextual variations over space are usually specified using "fixed" coefficients - derived from location dummy variables - to assess their direct effect on house values. This is based on the assumption that the marginal prices of structural housing attributes are invariant through space. This stable price assumption does not hold if markets are heterogeneous - as they are -, with various types of households having different needs and preferences while not being, at the same time, distributed evenly within urban areas. Such heterogeneity may result in locally distorting the demand for specific structural attributes and amenities of homes, thereby creating significant geographical trends that should be reflected in the coefficients of hedonic models (Páez et al., 2001; Thériault et al., 2003). It is also a major source of spatial autocorrelation among residuals if not adequately handled in the model specification (Can, 1990 \& 1993).

According to Griffith (1992, p. 278), "spatial autocorrelation may be defined as an average correlation between observations based upon replicated realisations of the geographic distribution of some attribute." It is often linked to diffusion processes occurring in geographical space. Exogenous effects, whose spatial distribution ultimately results in urban density gradients (Anselin and Can, 1986), can actually be manifold, ranging from city-wide structural factors to local externalities. As stated above, autocorrelation is highly detrimental to the efficiency of statistical tests used to assess the statistical significance of OLS regression coefficients (Anselin, 1990a \&1990b; Beron et al., 2001). Consequently, there is a clear need to test, and eventually incorporate, interactions between the structural characteristics of urban space and those housing specifics which are putatively linked to them. 
In applied regression analysis, two methodological concerns should be addressed: [1] testing for the presence of spatial heterogeneity and [2] implementing alternative estimation techniques. Since the early $1980 \mathrm{~s}$, quite a substantial body of literature has emerged out of these concerns (Cliff and Ord, 1981; Getis, 1990; Getis and Ord, 1992; Can, 1992; Ord and Getis, 1995; Griffith, 1996; Orford, 2000) and various approaches have been developed. As spatial dependence may not always be modelled adequately using additional descriptive geographical variables, one way of dealing with the problem is to introduce spatial autoregressive (SAR) terms into the hedonic function, which may then be written as:

$$
\mathbf{y}=\mathbf{X} \boldsymbol{\beta}+\boldsymbol{\rho} \mathbf{W} \mathbf{y}+\varepsilon
$$

where $\boldsymbol{X}$ is the matrix of explanatory variables, $\varepsilon$ the error term, $\boldsymbol{W} \boldsymbol{y}$ a weighted, spatially lagged dependent variable and $\rho$ the spatial autoregressive parameter, that is, the degree to which the values at individual locations depend on their neighbouring values (Fotheringham et al., 2002; Besner, 2002).

SAR terms may take several forms; most often though, they are weighted lagged values of the dependent variable (as in Equation 21) or of the error term. Spatially dependent variables can also be transformed prior to modelling into their spatial and non spatial components, using spatial filtering techniques (Cliff and Ord, 1981; Getis, 1995; Getis and Griffith, 2002; Griffith, 1996 \& 2000). While the two methods may be used in combination, it is more suitable for SAR terms to be included in a second step, only where spatial filtering has not managed to account for all heterogeneity (Can, 1990). Finally, semi-parametric approaches have also been developed to deal with spatial heterogeneity of real estate markets (Pavlov, 2000).

\subsection{Correcting for Spatial Heterogeneity - A Comparison of Two Approaches}

In this section, two regression-based methods designed at accounting for the spatial heterogeneity of regression parameters are empirically tested and compared as to their respective ability to explain spatial drifts and diminish, or remove, spatial dependence (Kestens et al., 2006): these are the OLS with spatial expansion method (SEM) developed by Casetti (1972 \& 1997) and the Geographically Weighted Regression (GWR) (Brunsdon et al., 1996; Fotheringham et al., 2002). 


\subsubsection{Casetti's spatial expansion method:}

The spatial expansion method developed by Casetti was initially designed at analyzing the spatial drift inherent in several socio-economic phenomena such as migration (Casetti, 1986) or labour markets (Pandit and Casetti, 1989). It was later on applied to property markets and price analysis (Can, 1990 \& 1992; Casetti, 1997; Thériault et al., 2003). Essentially, the SEM "extends" fixed parameters by introducing interactive variables combining a previously defined fixed characteristic with a context-sensitive, space-dependent variable. The hedonic equation may then be expressed as:

$$
\mathbf{y}=\mathbf{X} \boldsymbol{\beta}+\left((\mathbf{C E}) \mathbf{X}^{t}\right) \mathbf{1}+\varepsilon,
$$

where the second, expanded term accounts for interactions between basic housing attributes and context-sensitive variables (neighbourhood or household-related features).

Thus, statistically significant interactive parameters provide a measure of the implicit, local value people assign to attributes. Consequently, parameters that emerge as non significant overall may, when used in interaction, become highly significant, thereby revealing the existence of some spatial drift (Thériault et al., 2003) that would otherwise go unnoticed.

\subsubsection{The GWR approach:}

With the GWR approach, moving regression functions are estimated for every sampling point in a regular grid, using all data within a certain region around this point for calibration. The resulting parameters are site-specific and can therefore vary through space. Furthermore, a weighting scheme may be designed, whereby a spatial kernel is applied in order to give greater influence to close data points. The spatial kernel may be fixed (identical for all locations) or adaptive, in which case its bandwidth will vary with the density of the data. Several methods exist for identifying the bandwidth that yields the optimal trade-off between goodness-of-fit and degrees of freedom. We thus obtain:

$$
y_{i}=\beta_{0}\left(u_{i}, v_{i}\right)+\sum_{k} \beta_{k}\left(u_{i}, v_{i}\right) x_{i k}+\varepsilon_{i}
$$

where $\left(u_{i}, v_{i}\right)$ denotes the coordinates of the $i^{\text {th }}$ point in space and $\beta_{k}\left(u_{i}, v_{i}\right)$ is a realisation of the continuous function $\beta_{k}(u, v)$ at point $i$ (Fotheringham et al., 2002). 
A GWR application by Brunsdon et al. (1999) on residential values in Deal, South-Eastern England, shows that the relationship between house price and size varies significantly through space.

\subsection{Correcting for Spatial Heterogeneity - A Comparison of Two Approaches}

In this sub-section, SEM and GWR are applied to a sample of 761 single-family houses sold between 1993 and 2001 (between 1993 and 1996 mainly) in Quebec City, Canada (Kestens et al., 2006). In addition to basic land, building and local tax features, models control for several other dimensions, namely: [1] accessibility to urban services, expressed as mean time-distance by car to main activity centres (MAC); [2] surrounding vegetation (Kestens et al., 2004), which was found to exert strong influences on Quebec City's housing markets (Des Rosiers et al., 2002); [3] information on buyer's household profile obtained through a phone survey carried out from 2000 to 2003 (Kestens, 2004); and [4] socio-economic and housing stock information derived from Census data.

In this paper, only models that include all variables are discussed and compared. An overall comparison of performances obtained with SEM and GWR is presented in Exhibit 8. In both cases, the percentage of explanation of the variance is similar (0.894 for the SEM vs. 0.892 for the GWR), as is the global autocorrelation among their residuals (Moran's I values standing at 0.102 and 0.082 , respectively). Concerning the local autocorrelation, the number of significant LISA $z \mathrm{G}^{*} \mathrm{i}$ statistics (26) is identical, although these hot spots do not strictly match spatially (not shown here). In the end, these models are similar in terms of both explanatory power and ability to handle local and global spatial autocorrelation.

Let us now take a look at the way these two models handle heterogeneity. As findings suggest (for details, see Kestens et al., 2006), context-sensitive SEM coefficients, identified by the significant expansion terms, are as follows: Oven, Fireplace, Detached Garage (as found by Can 1990), Car Time to MAC, Woodlands_500m radius, Wooded, Agricultural Land_100m radius, NDVI_40m radius (density-of-vegetation Index) and \% Univ. Degree Holders. For these variables then, a single coefficient is not a valid alternative. Quite interestingly though, applying the GWR

procedure results in none of the model variables emerging as non-stationary, thereby suggesting that their implicit price is homogeneous over space. 
Table 8: An Overall Comparison of SEM and GWR Performances

\begin{tabular}{|c|c|c|}
\hline \multicolumn{3}{|c|}{$\begin{array}{c}\text { Dependent Variable: Ln Sale Price } \\
\text { Number of cases }=761\end{array}$} \\
\hline $\begin{array}{l}\text { Variables in } \\
\text { Model }\end{array}$ & $\begin{array}{l}\text { Property specifics } \\
\text { Accessibility } \\
\text { Land use and Vegetation in buffers around each property } \\
\text { Buyer's Household-level attributes } \\
1996 \text { Census data (Enumeration area-level) } \\
\text { For OLS Model: Interactions (Household attributes * others variables) }\end{array}$ & \\
\hline \multicolumn{3}{|c|}{ OLS / SEM Model } \\
\hline $\begin{array}{c}\text { Model } \\
\text { Adjustment }\end{array}$ & $\begin{array}{l}\text { R-square } \\
\text { Adj. R-Square } \\
\text { SEE } \\
\text { SEE in \% } \\
\text { F ratio } \\
\text { Sig. } \\
\text { Df1/Df2 } \\
\text { Interactive Variables / Total Variables } \\
\text { Maximum Variance Inflation Factor value } \\
\end{array}$ & $\begin{array}{c}0.894 \\
0.889 \\
0.104 \\
10.9 \% \\
161 \\
0.000 \\
38 / 722 \\
11 / 38 \\
3.9 \\
\end{array}$ \\
\hline $\begin{array}{l}\text { Spatial Auto- } \\
\text { correlation of } \\
\text { Residuals }\end{array}$ & $\begin{array}{l}\text { Moran's I (within } 1500 \mathrm{~m} \text { lag) } \\
\text { Sig. } \\
\text { Most sig. Moran's I SA range ( } 300 \mathrm{~m} \text { lags) } \\
\mathrm{Nb} \text { of significant LISA zG*i statistics }(600 \mathrm{~m} \text { lag, sig. } 0.05) \\
\mathrm{Nb} \text { of significant LISA zGi statistics }(600 \mathrm{~m} \text { lag, sig. } 0.05) \\
\end{array}$ & $\begin{array}{c}0.102 \\
0.218 \\
600-900 \\
26 \\
17 \\
\end{array}$ \\
\hline \multicolumn{3}{|c|}{$\begin{array}{c}\text { GWR Hedonic Model } \\
\end{array}$} \\
\hline $\begin{array}{c}\text { Model } \\
\text { Adjustment }\end{array}$ & $\begin{array}{l}\text { R-square } \\
\text { SEE } \\
\text { Kernel bandwidth (meters) } \\
\text { F statistic of GWR Improvement (sig.) } \\
\end{array}$ & $\begin{array}{c}0.892 \\
0.1059 \\
706.5 \\
2.51(0.013) \\
\end{array}$ \\
\hline $\begin{array}{l}\text { Spatial Auto- } \\
\text { correlation of } \\
\text { Residuals }\end{array}$ & $\begin{array}{l}\text { Moran's I (within } 1500 \mathrm{~m} \text { lag) } \\
\text { Sig. } \\
\mathrm{Nb} \text { of significant LISA zG*i statistics ( } 600 \mathrm{~m} \text { lag, sig. } 0.05) \\
\mathrm{Nb} \text { of significant LISA zGi statistics }(600 \mathrm{~m} \text { lag, sig. } 0.05)\end{array}$ & $\begin{array}{l}0.082 \\
0.265 \\
26 \\
20\end{array}$ \\
\hline
\end{tabular}


A possible explanation for this contradiction may lie with the a-spatial character of the heterogeneity identified in the expansion model, which brings out household heterogeneity not captured by the GWR procedure. Further research is needed to elucidate this issue.

To summarize, both methods yield highly interesting results and leads to the conclusion that social and spatial heterogeneity, while linked to one another, are not strictly equivalent, at least in Quebec City. Whereas the OLS spatial expansion method makes it possible to consider both the spatial and the non-spatial heterogeneity of regression parameters, the GWR approach provides interesting information through local regression statistics; it does not, however, allow identifying the process behind the parameter drift. Casetti's SEM, on the contrary, while less precise locally, makes it possible to explicitly consider actual processes lying at the root of non-stationarity, thereby helping disentangling the complex interactions shaping property values. 
Exhibit 9: Local Spatial Autocorrelation for SEM and GWR Models

a) Significant $z G * i$ statistics for SEM Hedonic Model

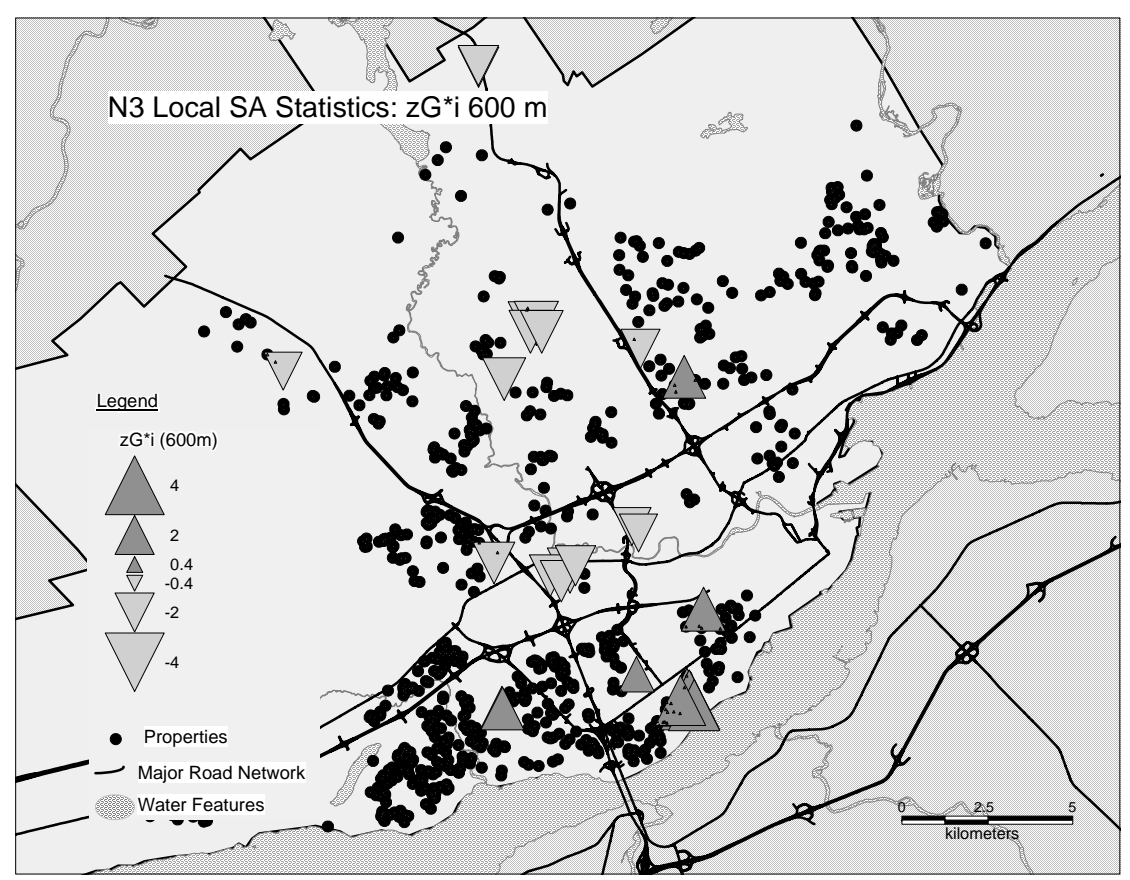

b) Significant $\mathrm{zG}^{*}$ i statistics for GWR Hedonic Model

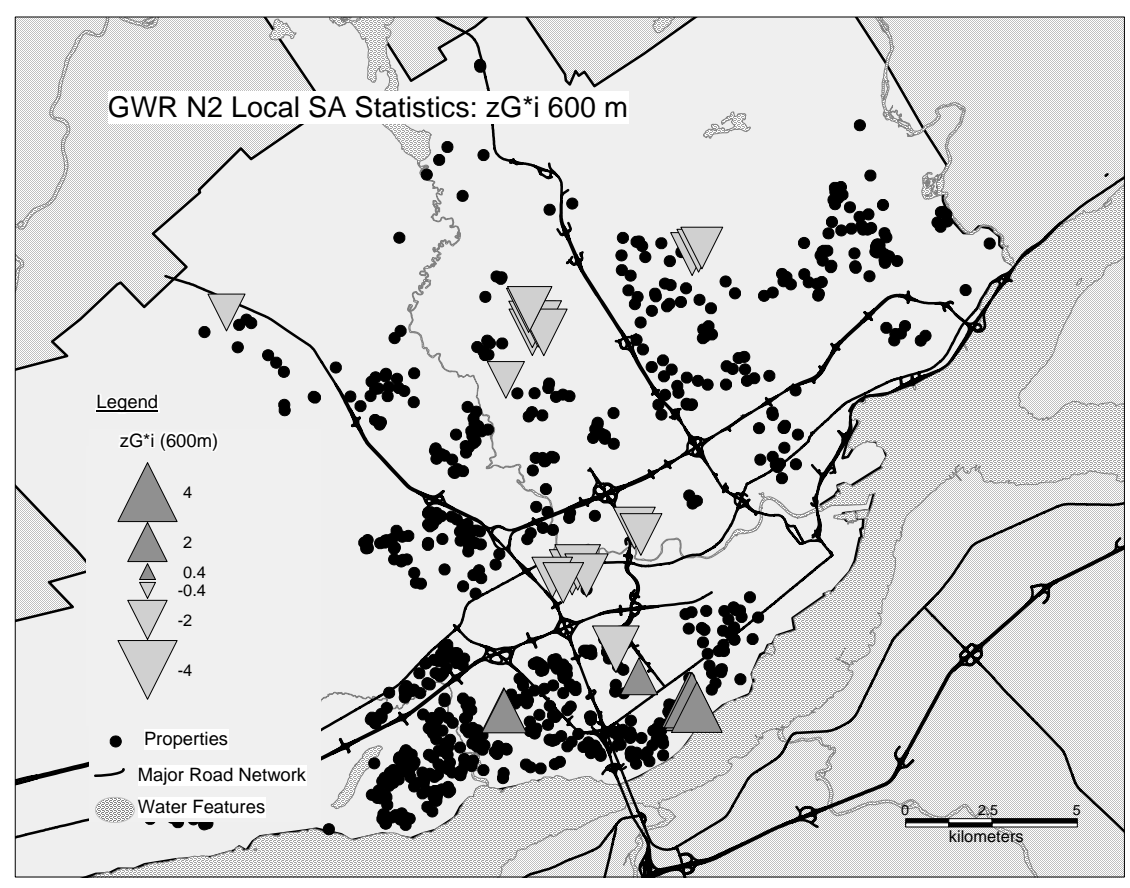




\section{CONCLUDING COMMENTS}

This paper has addressed several issues in relation to the applicability of the hedonic framework as a reliable device for estimating property values in an appraisal context. Each issue addressed here is in itself a field of research which has already triggered numerous productions and innovations and still deserves being further investigated.

Based on recent empirical research performed in a Canadian context, it has been shown that hedonics is a most powerful analytical method which conveys more advantages than drawbacks. Indeed, the method developed by Rosen more than three decades ago has constantly progressed, gaining in efficiency and reliability, and has adapted to new methodological challenges, often by borrowing to other disciplines.

The success of hedonics in urban and real estate economics and related fields stems from the sound conceptual framework it relies on as well as on the transparency of the approach. The latter promotes market intelligence and requires from the analyst that he put understanding of underlying processes above the mere search for a solution. 


\section{REFERENCES}

Adair, A.S., Berry, J.N. and McGreal, W.S. (1996). Hedonic Modelling, Housing Submarkets and Residential Valuation, Journal of Property Research, 13: 67-83.

Anselin, L. (1990a). Some Robust Approaches to Testing and Estimation in Spatial Econometrics, Regional Science and Urban Economics, 20: 141-163.

Anselin, L. (1990b). Spatial Dependence and Spatial Structural Instability in Applied Regression Analysis, Journal of Regional Science, 30(2): 185-207.

Anselin, L. and Can, A. (1986). Model Comparison and Model Validation Issues in Empirical Work on Urban Density Functions, Geographical Analysis, 18: 179-197.

Anselin, L. and Rey, S. (1991). Properties of Tests for Spatial Dependence in Linear Regression Models, Geographical Analysis, 23(2): 112-131.

Axhausen, K.W. and T. Gärling (1992). Activity-based approaches to travel analysis: Conceptual frameworks, models, and research problems, Transport Reviews, 12: 323-341.

Bajic, V. (1985). Housing Market Segmentation and Demand for Housing Attributes: Some Empirical Findings, AREUEA Journal, 13(1): 58-75.

Bajari, P. and M. Kahn (2005). Estimating Housing Demand with an Application to Explaining Racial Segregation in Cities, Journal of Business and Economic Statistics, 23(1): 20-33.

Basu, S. and Thibodeau, T. G. (1998). Analysis of Spatial Autocorrelation in House Prices, The Journal of Real Estate Finance and Economics, 17(1): 61-86.

Benjamin, J. D., Boyle, G. W. and Sirmans, C. F. (1990). Retail Leasing: Determinants of Shopping Center Rents, AREUEA Journal, 18(3): 302-312.

Benkard, C. and P. Bajari (2005). Hedonic Price Indexes with Unobserved Product Characteristics, and Application to PC's, Journal of Business and Economic Statistics, 23(1): 61-75.

Beron, K., Hanson, Y., Murdoch, J. and Thayer, M. (2001). Hedonic Price Functions and Spatial Dependence: Implications for the Demand for Urban Air Quality, in New Advances in Spatial Econometrics, Eds. L. Anselin \& R Florax (Springer-Verlag, New-York).

Berry, S., J. Levinsohn and A. Pakes (1995). Automobile Prices in Market Equilibrium, Econometrica, 63(4): 841-89.

Berry, B. J. L. and Bednarz, R..S. (1979). The disbenefits of neighbourhood and environment to urban property, in Segal, D., The Economics of Neighborhood, Academic Press, N.Y., 219-246.

Besner, C. (2002). A Spatial Autoregressive Specification with a Comparable Sales Weighting Scheme, Journal of Real Estate Research, 24: 193-211.

Boots, B. and P. Kanaroglou (1988). Incorporating the effects of spatial structure in discrete choice models of migration, Journal of Regional Science, 28: 495-507.

Box, G. E. P. and D. R. Cox (1964). An analysis of transformations, Journal of the Royal Statistical Society, 26: 211-243.

Brunsdon, C.F., Fotheringham, A.S. and Charlton, M.E. (1996). Geographically Weighted Regression: A Method for Exploring Spatial Non-stationarity. Geographical Analysis 28:281298.

Brunsdon, C., Aitkin, M., Fotheringham, A.S. and Charlton, M. (1999). A Comparison of Random Coefficient Modeling and Geographically Weighted Regression for Spatially Nonstationarity Regression Problems, Geographical and Environmental Modelling, 3: 47-62. 
Brunsdon, C.F., Fotheringham, A. S. and Charlton, M. (2002). Geographically Weighted Summary Statistics - A Framework for Localised Exploratory Data Analysis, Computers, Environment and Urban Systems, 26: 501-524.

Can, A. (1990). The Measurement of Neighbourhood Dynamics in Urban House Prices, Economic Geography, 66: 254-272.

Can, A. (1992). Residential Quality Assessment: Alternative Approaches Using GIS”, The Annals of Regional Science, 26: 97-110.

Can, A. (1993). Specification and Estimation of Hedonic Housing Price Models, Regional Science and Urban Economics, 22: 453-474.

Can, A. and Megbolugbe, I. (1997). Spatial Dependence and House Price Index Construction", Journal of Real Estate Finance and Economics, 14: 203-222.

Casetti, E. (1972). Generating Models by the Expansion Method: Applications to Geographical Research, Geographical Analysis, 4: 81-91.

Casetti., E. (1986). The Dual Expansion Method: An Application for Evaluating the Effects of Population Growth on Development, IEEE Transactions on Systems, Man, and Cybernetics, 16: 29-39.

Casetti, E. (1997). The Expansion Method, Mathematical Modeling, and Spatial Econometrics, International Regional Science Review, 20: 9-32.

Cliff, A. D., R. Martin and J.K. Ord (1974). Evaluating the friction of distance parameter in gravity models, Regional Studies, 8: 281-286.

Cliff, A. D. and Ord, J. K. (1981). Spatial Processes, Models and Applications, Pion Ltd., London.

Colwell, P.F (1990). Power Lines and Land Values, Journal of Real Estate Research, 5(1): 117127.

Colwell, P.F., Gujral, S.S. and Coley, C. (1985). The Impact of a Shopping Center on the Value of Surrounding Properties, Real Estate Issues, 10(1): 35-39.

Court, A.T. (1939). Hedonic Price Indexes with Automotive Examples, in The Dynamics of Automobile Demand, General Motors Corporation, New-York, 99-117.

Curry, L. (1972). Gravity analysis of gravity flows, Regional Studies, 6: 131-147.

Delaney, C.J. and D. Timmons (1992). High Voltage Power Lines: Do They Affect Residential Property Value?, Journal of Real Estate Research, 7(3): 315-29.

Des Rosiers, F. (2002). Power Lines, Visual Encumbrance and House Values : A Micro-spatial Approach to Impact Measurement, The Journal of Real Estate Research, 23(3): 275-300.

Des Rosiers, F. and M. Thériault (1996). Rental Amenities and the Stability of Hedonic Prices: A Comparative analysis of Five Market Segments, Journal of Real Estate Research, 12(1): 17-36.

Des Rosiers, F., A. Lagana, M. Thériault and M. Beaudoin (1996). Shopping Centers and House Values: an Empirical Investigation, Journal of Property Valuation \& Investment, 14(4): 41-63.

Des Rosiers, F. and Thériault, M. (1999). House Prices and Spatial Dependence: Towards an Integrated Procedure to Model Neighborhood Dynamics. Laval University, Faculty of Business Admin., Québec, WP\# 1999-002.

Des Rosiers, F., A. Bolduc and M. Thériault (1999). Environment and Value: Does Drinking bWater Quality Affect House Prices ? The Journal of Property Investment and Finance, 17(5): 444-463.

Des Rosiers, F., M. Thériault and P.-Y. Villeneuve (2000). Sorting out Access and Neighbourhood Factors in Hedonic Price Modelling, The Journal of Property Investment and Finance, 18(3): 291-315. 
Des Rosiers, F., A. Lagana and M. Thériault (2001). Size and Proximity Effects of Primary Schools on Surrounding House Values, Journal of Property Research, 18(2): 149-168.

Des Rosiers, F., Thériault, M., Kestens, Y. and Villeneuve, P-Y. (2002). Landscaping and House Values: an Empirical Investigation, The Journal of Real Estate Research, Special Issue, 23:(1), 139-61.

Des Rosiers, F., M. Thériault and L. Ménétrier (2005). Spatial Versus Non-Spatial Determinants of Shopping Center Rents : Modeling Location and Neighborhood-Related Factors, Journal of Real Estate Research, 27(3): 293-319.

Dubin, R. A. (1988). Estimation of Regression Coefficients in the Presence of Spatially Autocorrelated Error Terms, Review of Economics and Statistics, 70: 466-474.

Dubin, R. A. (1992). Spatial Autocorrelation and Neighbourhood Quality, Regional Science and Urban Economics, 22: 433-452.

Epple, D. and G. J. Platt (1998). Equilibrium and Local Distribution in an Urban Economy When Households Differ in Both Preferences and Income, Journal of Urban Economics, 43: 23-51.

Fotheringham, S. (1981). Spatial structure and distance-decay parameters, Annals of the Association of American Geographers, 71: 425-436.

Fotheringham, S. (1986). Modelling Hierarchical Destination Choice, Environment and Planning $A, 18: 401-418$.

Fotheringham, A.S., Brundson, F.C. and Charlton, M. (2002). Geographically weighted regression: The analysis of spatially varying relationships, John Wiley \& Sons, Chichester.

Getis, A. (1990). Screening for Spatial Dependence in Regression Analysis. Papers of the Regional Science Association, 69: 69-81.

Getis, A. (1995). Spatial filtering in a regression framework: Experiments on regional inequality, government expenditures, and urban crime, in New Directions in Spatial Econometrics, Eds. L. Anselin \& R Florax (Springer-Verlag, Berlin), pp. 172-188.

Getis, A. and Ord, J. K. (1992). The Analysis of Spatial Association by Use of Distance Statistics, Geographical Analysis, 24: 189-206.

Getis, A. and Griffith, D. A. (2002). Comparative Spatial Filtering in Regression Analysis, Geographical Analysis, 34: 130-140.

Goettler, R. and R. Shachar (2001). Estimating Spatial Competition in the Network Television Industry, RAND Journal of Economics, 32(4), 624-656.

Goodman, A. C. and Thibodeau, T. G. (1995). Age-Related Heteroskedasticity in Hedonic House Price Equations, Journal of Housing Research, 6: 25-42.

Goodman, A. C. and Thibodeau, T. G. (1997). Dwelling-Age-Related Heteroskedasticity in Hedonic House Price Equations: An Extension, Journal of Housing Research, 8: 299-317.

Goodman, A. C. and T. G. Thibodeau (2003). Housing Market Segmentation and Hedonic Prediction Accuracy, Journal of Housing Economics, 12: 181-201.

Gorman, T. (1980). A Possible Procedure for Analysing Quality Differentials in the Egg Market, Review of Economic Studies, 47(5): 843-856.

Graves, P., J. C. Murdoch, M. A. Thayer and D. Waldman (1988). The Robustness of Hedonic Price Estimation: Urban Air Quality, Land Economics, 64(3): 220-33.

Grether, M. D. and Mieszkowski, P. (1980). The Effects of Non-Residential Land Uses on the Prices of Adjacent Housing: Some Estimates of Proximity Effects, Journal of Urban Economics, 8(1): 1-15.

Griffith, D. A. (1992). What Is Spatial Autocorrelation? Reflections on the Past 25 Years of Spatial Statistics, L'Espace géographique, 21(3): 265-280.

Griffith, D. A. (1996). Spatial Autocorrelation and Eigenfunctions of the Geographic Weights Matrix Accompanying Geo-Referenced Data, The Canadian Geographer, 40: 351-367. 
Griffith, D.A. (2000). A linear Regression Solution to the Spatial Autocorrelation Problem, Journal of Geographical Systems, 2: 141-156.

Griliches, Z. (1961). Hedonic Price Indexes for Automobiles: An Econometric Analysis of Quality Change, in The Price Statistics of the Federal Government, General Series, National Bureau of Economic Research, 73: 137-196.

Griliches, Z. (1971). Hedonic Price Indexes Revisited, in Price Indexes and Quality Change, Federal Reserve Board, Massachusetts, 3-15.

Guntermann, K.L. and Colwell, P.F. (1983). Property Values and Accessibility to Primary Schools, Real Estate Appraiser \& Analyst, 49(1): 62-8.

Hamilton, S. W. and G.M. Schwann (1995). Do High Voltage Electric Transmission Lines Affect Property Value ?, Land Economics, 71(4): 436-44.

Handy, S.L. and D.A. Niemeier (1997). Measuring accessibility: an exploration of issues and alternatives, Environment and planning A, 29(7): 1175-1194.

Hansen, W.G. (1959). How accessibility shapes land use, Journal of American Institute of Planners, 25: 73-76.

Hanson, S. (1995). Getting there: Urban transportation in context, In S. Hanson (Ed.) The Geography of Urban Transportation. New York, The Guilford Press, pp. 3-25.

Hoch, I. and Waddell, P. (1993). Apartment rents: another challenge to the monocentric model, Geographical Analysis, 25(1): 20-34.

Hoesli, M., C. Giacotto and P. Favarger (1997a). Three New Real Estate Price Indices for Geneva, Switzerland, Journal of Real Estate Finance and Economics, 15(1): 93-109.

Hoesli M., Thion B. and Watkins C. (1997b) A hedonic investigation of the rental value of apartments in central Bordeaux. Journal of Property Research, 14: 15-26.

Hotelling, H. (1933). Analysis of a Complex of Statistical Variables into Principal Components, Journal of Educational Psychology, 24: 417-441; 498-520.

Johnston, R.J. (1973). On friction of distance and regression coefficients, Area, 5: 187-191.

Jud, G. D. and D. T. Winkler (1991). Location and Amenities in Determining Apartment Rents: An Integer Programming Approach, Appraisal Journal, 59(2): 266-75.

Kestens, Y. (2004). Land Use, Accessibility and Household Profiles: Their Effects on Residential Choice and House Values, Ph.D. Thesis, Laval University, Quebec, Canada.

Kestens, Y., M. Thériault and F. Des Rosiers (2004). The Impact of Surrounding Land Use and Vegetation on Single-Family House Prices, Environment \& Planning B - Planning and Design, 31: 539-567.

Kestens, Y., M. Thériault and F. Des Rosiers (2006). Heterogeneity in Hedonic Modelling of House Prices: Looking at Buyers' Household Profiles, Journal of Geographical Systems, 8(1): 61-96.

Kim, H.M and M.P. Kwan (2003). Space-time Accessibility Measures: A Geocomputational Algorithm with a Focus on the Feasible Opportunity Set and Possible Activity Duration, Journal of Geographical Systems, 5: 71-91.

King, L. J. (1969). Statistical Analysis in Geography, Prentice-Hall, Englewood Cliffs, N.J.

Kinnard, W. N. Jr, and S. A. Dickey (1995). A Primer on Proximity Impact Research: Residential Property Values Near High-Voltage Transmission Lines, Real Estate Issues, 20(1): 23-29.

Lancaster, K. (1966). A New Approach to Consumer Theory, The Journal of Political Economy, 74(2): 132-157.

Levinson, D.M. (1998). Accessibility and the journey to work, Journal of Transport Geography, 6: $11-21$. 
Levy, J. and M. Lussault (2003). Dictionnaire de la géographie et de l'espace des sociétés, Paris, Bélin.

Linneman, P. (1980). Some Empirical Results on the Nature of the Hedonic Price Function for the Urban Housing Market, Journal of Urban Economics, 8(1): 47-68.

Mejia, Luis C. and Benjamin, John, D. (2002). What Do We Know About the Determinants of Shopping Center Sales ? Spatial vs. Non-Spatial Factors, Journal of Real Estate Literature, 10(1): pp. 3-26.

Neter, J., Wasserman, W. and Kutner, M. H. (1985). Applied Linear Statistical Models, 2nd ed., R. D. Irwin, Homewood, IL, pp. 391-392.

Nevo, A. (2001). Measuring Market Power in the Ready-To-Eat Cereal Industry, Econometrica, 69(2): 307-342.

Ord, J. K. and Getis, A. (1995). Local Spatial Autocorrelation Statistics, Geographical Analysis, 27: 286-306.

Orford, S. (2000). Modelling Spatial Structures in Local Housing Market Dynamics: A Multilevel Perspective, Urban Studies, 37: 1643-1671.

Pace, R. K., Barry, R. and Sirmans, C. F. (1998). Spatial Statistics and Real Estate, The Journal of Real Estate Finance and Economics, 17(1): 5-14.

Páez, A., Uchida, T. and Miyamoto, K. (2001). Spatial Association and Heterogeneity Issues in Land Price Models, Urban Studies, 38: 1493-1508.

Pandit, K. and Casetti, E. (1989). The shifting patterns of sectoral labor allocation during development: Developed versus developing countries, Annals of the Association of American Geographers, 79: 329-344.

Pavlov, A. D. (2000). Space-Varying Regression Coefficients: A Semi-Parametric Approach Applied to Real Estate Markets, Real Estate Economics, 28(2): 249-283.

Stone, R. (1956). Quantity and Price Indexes in National Accounts, Organisation de la coopération économique d'Europe, Paris.

Richardson, H. W. (1977). On the Possibility of Positive Rent Gradients, Journal of Urban Economics, 4(1): 60-68.

Rosen, S. (1974). Hedonic Prices and Implicit Markets: Product Differentiation in Pure Competition, The Journal of Political Economy, 82: 34-55.

Rummel, R.J. (1970). Applied Factor Analysis, Evanston, Northwestern University Press.

Simons, R. A. and J. D. Saginor (2006). A Meta-Analysis of the Effect of Environmental Contamination and Positive Amenities on Residential Real Estate Values, Journal of Real Estate Research, 28(1): 71-104.

Sirmans, G. S. and J. D. Benjamin (1989). Determining Apartment Rent: The Value of Amenities, Services and External Factors, Journal of Real Estate Research, 4(2): 33-43.

Sirmans, G. S. and J. D. Benjamin (1991). Determinants of Market Rent, Journal of Real Estate Research, 6(3): 357-79.

Sirmans, C. F. and Guidry, K. A. (1993). The Determinants of Shopping Centre Rents, The Journal of Real Estate Research, 8(1): 107-115.

Straszheim, M. (1987). The theory of urban residential location, in Handbook of Regional and Urban Economics, Ed. Edwin S. Mills, Amsterdam, North Holland, 2001-2060.

Tabachnick, B. G. and L.S. Fidell (1996). Using Multivariate Statistics, HarperCollins College Publishers, New York, p. 636.

Thériault, Marius and F. Des Rosiers (1995). Combining Hedonic Modeling, GIS and Spatial Statistics to Analyze Residential Markets in the Quebec Urban Community in Proceedings of 
the Joint European Conference and Exhibition on Geographical Information, March 26-31, The Hague, Netherlands, Vol. 2, pp. 131-136.

Thériault, M., M.H. Vandersmissen, M. Lee-Gosselin and D. Leroux (1999). Modelling commuter trip length and duration within GIS: Application to an O-D survey, Journal for Geographic Information and Decision Analysis, 3(1): 41-55.

Thériault, M., F. Des Rosiers, P.-Y. Villeneuve and Y. Kestens. (2003). Modelling Interactions of Location with Specific Value of Housing Attributes, Journal of Property Management, 21:1, 25-62.

Thériault, M. and F. Des Rosiers (2004). Modelling perceived accessibility to urban amenities using fuzzy logic, transportation GIS and origin-destination surveys, In F. Toppen and P. Prastacos (Eds.) Proceedings of AGILE $20047^{\text {th }}$ Conference on Geographic Information Science, Crete University Press, Heraklion, Greece, pp. 475-485.

Thériault M., F. Des Rosiers and F. Joerin (2005). Modelling Accessibility to Urban Services Using Fuzzy Logic: A Comparative Analysis of Two Methods, Journal of Property Investment and Finance, 23(1): 22-54.

Tiefelsdorf, M. (2003). Misspecification in interaction model distance decay relations: A spatial structure effect, Journal of Geographical Systems, 5: 25-50.

Tyrvainen, L. (1997). The amenity value of the urban forest: an application of the hedonic pricing method, Landscape and Urban Planning, 37: 211-222.

Worzala, E., Lenk, M. and Silva, A. (1995). An Exploration of Neural Networks and its Application to Real Estate Valuation, Journal of Real Estate Research, 10: 185-201. 